\title{
The Political Economy of Regional Integration Projects at Borders where Rich and Poor Meet: The Role of Cross-Border Shopping and Community Sorting
}

\author{
KRISTOF DASCHER \\ ALEXANDER HAUPT
}

CESIFO WORKING PAPER No. 2280

CATEgory 2: Public CHOICE

APRIL 2008

\footnotetext{
An electronic version of the paper may be downloaded

- from the SSRN website: $\quad$ www.SSRN.com

- from the RePEc website: $\quad$ www.RePEc.org

- from the CESifo website: www.CESifo-group.org/wp
} 


\title{
The Political Economy of Regional Integration Projects at Borders where Rich and Poor Meet: The Role of Cross-Border Shopping and Community Sorting
}

\begin{abstract}
At borders where rich and poor countries meet, services prices differ hugely. In principle, price differentials could be exploited to mutual benefit, offering improved job opportunities to the poor as well as better shopping opportunities to the rich. However, cross-border shopping is often limited by the substantial transaction costs of crossing the border. Moreover, local governments frequently fail to cut these transaction costs even where they have the opportunity to do so. In this paper, we show (i) why a majority of the local electorate often backs this outcome, (ii) how intra-country mobility affects local policy, and (iii) how (inter-) national regulations shape local decisions.
\end{abstract}

JEL Code: F15, H7, R2, D72.

Keywords: cross-border shopping, community sorting, regional integration, voting, federalism.

\author{
Kristof Dascher \\ European University Viadrina \\ Economics Department \\ P.O. Box 1786 \\ Germany - 15207 Frankfurt (Oder) \\ dascher@euv-frankfurt-o.de
}

\author{
Alexander Haupt \\ University of Plymouth \\ Plymouth Business School \\ Plymouth, Devon PL4 8AA \\ United Kingdom \\ alexander.haupt@plymouth.ac.uk
}

March 2008

We thank Andreas Heigl, Georg Hirte, Wolfgang Peters and Hermann Ribhegge for valuable comments and criticism. We have also benefitted from discussions at conferences of the German Research Foundation (DFG), the CESifo Dresden, the European Trade Study Group, the Verein für Socialpolitik and its Committee for Population Economics. A Haupt gratefully acknowledges financial support from the German Research Foundation (DFG) within the Priority Programme SPP 1142. This paper was partly written while he was visiting the Center for Economic Studies (CES) at the University of Munich. A Haupt is grateful to the members of CES and the Economics Department for their hospitality and for stimulating discussions, and to CES for financial support for this research visit. 


\section{Motivation}

Services are expensive in rich countries. Yet rich countries often have poor neighbours where the same services are cheaper. Service price disparity and the geographical proximity of rich and poor countries then coincide to the mutual benefit of the neigbouring borderlands. Rich shoppers can buy services more cheaply on the poor side of the border than they could at home, while the sellers of these services can charge these buyers more than they could local buyers. Indeed, cross-border shopping in services is a visible part of daily life along many international borders. US borderlanders consume services in neighbouring Mexico, as do Polish borderlanders in neighbouring Ukraine, Italian borderlanders in adjacent Slovenia, and those of Russia's far eastern Vladivostok in nearby Chinese cities.

We emphasise that service prices can differ hugely. A hair cut in a poor country, say, may cost as little as one fifth of what its rich neighbour equivalent costs, with no difference in quality. Moreover, cross-border sales can make a substantial contribution to the volume of bilateral trade. For these reasons we suggest that cross-border shopping can not only improve shopping opportunities for the rich, it can also increase job opportunities for the poor.

However, potential gains from cross-border shopping often are a long way from being fully exploited. Popular explanations point to the transaction costs of crossing borders. Of course, annoying border controls and insufficient infrastructure surely play an important role. Ultimately, however, the transaction costs induced cannot explain the low level of cross-border shopping observed; transaction costs must be seen as being politically determined rather than being exogenously given. Within a framework defined by (inter)national politics, local governments could still carry out regional integration projects that would slash transaction costs. They could, for example, improve the local cross-border infrastructure and public transport. And many of these projects would be welfare enhancing, with the aggregate benefits of these projects that result from lower transaction costs exceeding their respective costs. So the interesting question is why local authorities might fail to reduce transaction costs, and hence might fail to realise the full gains from cross-border shopping. For instance, just recently, a proposal to link Frankfurt and Slubice, a twin city pair on the Polish-German border, by public tram was rejected by Frankfurt voters and was shelved.

In this paper, we provide a political economy explanation for cross-border shopping being inefficiently low. Specifically, we show (i) how this outcome can result from local political inaction backed by a majority of the electorate, (ii) how local policy is shaped by the interaction between borderland populations and their respective hinterland populations, and (iii) how local decisions embedded in a federal structure are related to (inter-)national regulations. Our explanation builds on two key characteristics where individuals differ: cultural ability and interregional mobility.

The term cultural ability refers to an individual's ability to interact with individ- 
uals whose cultural background is profoundly different from her own. It captures the psychological cost of serving, or being served by, those from the border's other side. The term interregional mobility refers to the ease with which an individual moves from a country's borderland to its respective hinterland, and vice versa. It stands for her 'emotional' attachment-to-home. Individuals differ in both cultural ability and interregional mobility. Jointly these two heterogeneities are at the heart of the distributional conflicts that eventually give rise to inefficient policies.

Heterogenous cultural ability generates both winners and losers of local integration projects among borderland natives. And heterogenous mobility prevents perfect community sorting according to political preferences. But even the imperfect sorting that can occur feeds back into the distributional implications of integration projects and thus into their political appeal. Mobility - which can be interpreted as a measure for intracountry integration - shapes cross-border integration policy in the borderlands.

We analyse the resulting interplay in a two-country-four-region model. In each country's border region there is a referendum on a regional integration project that would lower the transaction costs of cross-border shopping. The effectiveness of this project depends on exogenous national regulations. If the electorate approves the proposal, citizens can still escape the local taxes necessary to finance the project by moving to the respective hinterland. Hinterland natives, on the other hand, can move to their respective borderland to take advantage of its specific job or shopping opportunities. But these newcomers then also have to bear their share of the tax.

Starting from a situation in which transaction costs are high initially, we provide three major results: first, voting is biased against regional integration projects. Specifically, not only will a welfare reducing project (meaning that aggregate welfare gains from lower transaction costs fall short of project costs) never be approved, but a welfare enhancing project may also fail politically. More technically, while the feature 'welfare enhancing' is a necessary condition for a local integration project to succeed at the polls, it is not sufficient.

Second, a rise in intra-country mobility erodes the political support for integration projects, particularly (but not only) if borderland homes are owned by absentee landlords. This result is especially disturbing, given that at the same time higher mobility permits more efficient community sorting and thus raises the potential welfare gains from cross-border shopping. We argue that higher mobility tends to diminish realised welfare gains by impeding the integration project politically, thereby keeping transaction costs up.

Third, local support for the integration project is strengthened if central governments themselves take steps to cut transaction costs. In this sense, there is a complementarity between (inter-)national and regional policies. By contrast, federal grants do not necessarily raise the share of votes in favour of the regional project.

The paper looks at the potential of cross-border shopping and the political difficulties encountered by any attempts to make use of this potential. It highlights 
how two types of interactions that have not previously been associated with crossborder shopping - those between borderlands and hinterlands and those between local initiatives and national regulations - affect political failure. In particular, it points to the ways in which growing household mobility may drive a wedge between potential and realised welfare, and thereby provides a laboratory view of the ambiguities of 'globalisation'. All in all, the paper connects cross-border shopping to the political economy of local public infrastructure investment, to household sorting, to fiscal federalism, and, in a more figurative sense, to globalisation. We briefly address existing work on cross-border shopping, community sorting and voting, and also on the other themes related to our contribution:

Cross-border shopping is prominent in the literature on tax competition (see, e.g., Kanbur/Keen (1993) and, more recently, Haufler (2001), Lucas (2004) and Nielsen (2001, 2002)). In these papers, competing governments strategically set commodity taxes to attract cross-border shoppers and raise domestic tax revenues. Since crossborder shopping results from distortionary tax differentials between countries, it is welfare-reducing. By contrast, in our framework, cross-border shopping results from international productivity gaps and the induced producer price differentials. Taking advantage of these is generally welfare-enhancing.

However, the extent to which the comparative advantage can be utilised depends on the political decisions about the local integration project and on the types of individuals living in the border regions. In analysing these issues, our paper contributes to the literature on household mobility, public expenditures, and voting (see, e.g., Epple et al. (1984, 1993), Hansen/Kessler (2001), Kessler/Lülfesmann (2005) and Westhoff (1977)). These papers explore how different household types sort into communities when local voters decide on local expenditures on public goods or redistribution. In contrast to these contributions, we explicitly focus on the ambiguous role of mobility: its positive impact on potential welfare and its negative political impact on realised welfare. Considering cross-border projects, we analyse the link between international and regional integration, which is not considered in the literature above, and stress the role of different land ownership regimes. The criterion which induces sorting in the current context, namely the ability to interact with people of different cultures, should be new to a literature typically focusing on variation within a given country. ${ }^{1}$

Finally notice that some features of cross-border shopping and sorting also appear in other contexts, for instance, in connection with the 'maquiladoras' strung along the US-Mexican border. But, in that case, industries, not consumers, 'cross-border shop', taking advantage of the proximity to the other country and buying intermediate goods on the poor side of the border (see, e.g., Grunwald (1985), Hanson (1996, 2001)).

\footnotetext{
${ }^{1}$ E.g., common sorting criteria in the literature include income and preferences for local public goods (e.g., Kessler/Lülfesmann (2005)), race (e.g., Alesina et al. (2004)), peer effects (e.g., Calabrese et al. (2005)), and pro-social behavior (Lazear et al. (2006)).
} 
The plan of the paper is as follows. Section 2 introduces the model's central components. Section 3 discusses the 'Shopping and Migration (ShoMig) Equilibrium' that obtains for a given level of cross-border integration. Section 4 looks into ShoMig Equilibrium's comparative static properties with respect to political and other variables. Section 5 adds the political economy dimension by analysing how borderland voters (in full knowledge of the mechanisms discussed earlier) decide on a local integration project proposed to them. Section 6 analyses how majority outcomes vary with the central government constraints imposed on, and the subsidies given to, them. Section 7 discusses the model's results and sketches some political implications. Concluding remarks and suggestions for further research follow in section 8 .

\section{Building Blocks}

We start by presenting the building blocks of our four-region-two-country model of cross-border shopping and community sorting when local citizens vote on a crossborder integration project. Let us state the basic geographic, technological, individual and political features in turn.

Geography and Housing: The model's geography is straightforward enough. Neighbouring countries Poor $P$ and Rich $R$ consist of a border and interior region each. Poor Border $P B$ and Rich Border $R B$ are adjacent to one another. Their shared boundary is the border of the countries. Poor Interior $P I$ and Rich Interior $R I$ are the respective hinterlands of the border regions. Countries are indexed $j=$ $P, R$, proximity to the border is indexed $k=B, I$, and regions are indexed $j k=$ $P B, R B, P I, R I$. Individuals are born in either of these regions. The resulting number of people native to region $j k$ is $N_{j}$, i.e., country $j$ 's two regions $j B$ and $j I$ have identical native populations, for simplicity. Each individual always occupies one dwelling of unit size. So initially, the housing stock in region $j k$ is $N_{j}$, too. While housing stocks in border regions $j B$ remain fixed, stocks in interior regions $j I$ may subsequently be expanded, at a constant per unit cost $d_{j}$. (This assumption simplifies our analysis considerably. But, as discussed in section 6, our major qualitative results remain valid in a more general setting).

Technologies and Trade: An industrial good $x$ and a services good $y$ are produced with Ricardian technologies. Labour is perfectly mobile across sectors, and each labour unit employed in sector $x(y)$ produces $a_{j}\left(b_{j}\right)$ units of good $x(y)$ in $j$. Workers in Rich are better at producing $x$ than are workers in Poor, i.e., $a_{R}>a_{P}$, but are only equally good at providing $y$, i.e., $b_{R}=b_{P}=b$. These assumptions reflect the stylised fact that gaps in international productivity are much more pronounced in industry than in services. For convenience, productivities are normalised such that $b>1$ holds. We further assume that the industrial good $x$ is tradable and 
can be shipped at no cost while the services good $y$ is not tradable. However, the individuals residing in Rich Border can cross-border shop and buy the services good abroad in nearby Poor Border while those living and working in Poor Border can provide the services good for Rich shoppers. Going one step further, we assume that Poor Border's service suppliers can choose between serving Poor shoppers only and exclusively supplying Rich shoppers. Poor Border residents doing the latter are dubbed "cross-border sellers".

Interregional Mobility: Individuals from one country may shop, yet neither live nor work in the other country. Within either country, each citizen is free to choose the region in which she lives and works. Intra-country mobility, however, is imperfect and varies substantially across individuals. Some individuals are strongly attached to their native region, or find it difficult to integrate into a new environment. Others, by contrast, have only weak links to their home region or get in touch with people in new places easily. Let $m_{j k}^{h}$ denote such home attachment's pecuniary equivalent for native $h$ of region $j k$ (see, e.g., Mansoorian/Myers (1993)). We refer to this equivalent as migration costs, being the costs of moving from one's home region to the other region.

Cultural Ability: Individuals also differ in their cultural ability, i.e., their ability to interact with people from the other side of the border. This ability determines the cultural transaction costs (in short: cultural costs) of those involved in crossborder selling and shopping. Both sellers and shoppers need to become familiar with different sets of social norms. Moreover, sellers have to adapt their strategies to the needs of customers with a different cultural background and mother tongue while shoppers need to be aware of new business and legal rules. Finally, shoppers and sellers alike must tolerate close contact with someone earning a very different income (see the role of status in, e.g., Frank, 1987). Let $z_{j k}^{h}$ denote the resulting cultural costs for native $h$ from region $j k$ who cross-border shops or sells. Certainly the cultural cost of providing services to, or of being served by, foreigners varies across individuals. Generally costs are lower for those skilled in languages and able to blend in.

Heterogeneity: To capture the heterogeneity in interregional mobility and cultural ability simultaneously, we assume that characteristics of the natives to $j k$ are distributed according to a joint c.d.f. $F_{j}\left(m_{j k}, z_{j k}\right):\left[0, \bar{m}_{j}\right] \times\left[0, \bar{z}_{j}\right] \mapsto[0,1], \bar{m}_{j}, \bar{z}_{j}>0 .{ }^{2}$ More specifically, $z_{j k}$ and $m_{j k}$ are uniformly and independently distributed, implying joint density $f_{j}\left(m_{j k}, z_{j k}\right)=\left(\bar{m}_{j} \bar{z}_{j}\right)^{-1}$. We emphasise that $F_{j}$ is indexed by country only, instead of by country and region. The joint distribution of transaction and mobility costs is the same in both $j B$ and $j I$. Border and Interior natives are equally mobile and equally talented in inter-cultural interaction. Differences might, however, exist between the individuals in the two countries, particularly between the

\footnotetext{
${ }^{2}$ Cultural costs may be negative if individuals enjoy interacting with foreigners. Similarly, individual migration costs may be negative if the alternative region is preferred. For convenience, though, we restrict $m_{j k}$ and $z_{j k}$ to be positive.
} 
cultural costs of the sellers and the shoppers. Finally, note that information on $F_{j}$ is assumed to be common knowledge, while information on individual characteristics is not.

Property Rights: Housing property rights prove to be important for our conclusions. To show how the ownership structure shapes our results, we distinguish between two regimes of ownership. With native ownership, each individual owns the unit of housing she initially lives in. Then all Interior natives and Border natives are simply owner-occupiers initially. In contrast, with absentee ownership, only Interior natives own the housing they initially live in. Border natives no longer do. Instead each Interior native now owns one unit of the fixed housing stock in Border, and each Border native pays rent $r_{j B}$ to her respective Interior landlord. Both housing property rights regimes are captured by dummy $\alpha_{j}$, with

$$
\alpha_{j}= \begin{cases}1 & \text { for native ownership, and } \\ 0 & \text { under absentee ownership. }\end{cases}
$$

As we will discuss in section 6 , these two regimes are sufficient to cover the interesting cases. In particular, the regime in which Border natives own all land proves to be redundant.

Integration Project and Transaction Costs: Residents of Rich Border may buy services goods in nearby Poor Border, but shopping abroad incurs transaction costs for shoppers crossing the border in addition to the individual cultural costs of interacting with Poor's sellers. These transaction costs $\theta \in\left[0, p_{R}-p_{P}\right]$ represent the pecuniary equivalent of longer traveling time, particularly of time lost at border controls, and include additional transportation costs. They are identical for all shoppers. Decisions at the national and international level substantially frame these transaction costs $\theta$, by defining key parameters of the border crossing regime. Yet, within this framework, Border governments may still have sufficient leeway for political action. In particular, we assume that border regions can carry out an 'integration project' that would reduce transaction costs from $\bar{\theta}$ down to $\underline{\theta}$, with initial costs $\bar{\theta}$ and leeway $(\bar{\theta}-\underline{\theta})$ exogenously determined at the national levels. The integration project is approved if, and only if, it carries both Border regions by a majority of votes in each. Project costs are shared among Border Regions, with $e_{j}$ to be raised in $j B$ and cost shares $e_{j}$ exogenously given. Funding for project costs is raised lump sum among Borders' residents, with tax $t_{j B}$ simply given by

$$
t_{j B}=e_{j} / N_{j}
$$

Utility and Timing: Each individual supplies one unit of labour to its region of residence, and consumes one unit of services and housing each. Given our pecuniary equivalents $\theta, z_{j k}^{i}$, and $m_{j k}^{i}$ and defining the industrial good $x$ as numeraire good, individual utility can be expressed as

$$
U_{P k}^{h}=x_{P k}^{h}-\gamma_{z} z_{P k}^{h}-\gamma_{m} m_{P k}^{h} \quad \text { and } \quad U_{R k}^{h}=x_{R k}^{h}-\gamma_{z}\left(\theta+z_{R k}^{h}\right)-\gamma_{m} m_{R k}^{h},
$$


where $\gamma_{z}=1\left(\gamma_{m}=1\right)$ if native $h$ from region $j k$ cross-border shops or cross-border sells (migrates) and $\gamma_{z}=0\left(\gamma_{m}=0\right)$ otherwise.

Individuals need to make decisions at two stages. At stage 1, the countries' Border natives vote on the integration project simultaneously. At stage 2, every individual decides on whether to migrate or not, and, if she chooses to reside in Poor (Rich) Border, on whether to become cross-border seller (cross-border shopper) or not. Taxes that eventually result from the integration project are levied on the ultimate residents of the Borders. So Borders' natives can escape from taxation through migration. ${ }^{3}$ Individuals maximise their utility and are fully aware of how the voting outcome affects the succeeding location and occupation choices. All transactions are carried out in perfectly competitive markets. As usual, we solve the model by backward induction. The game's second stage is discussed in sections 3 and 4 . Treatment of the game's first stage follows then in section 5 .

\section{Cross-Border Shopping and Community Sorting}

In this section we analyse individual choices, community sorting, and cross-border shopping for given policy parameters $\left(\theta, t_{P B}, t_{R B}\right)$. To this end, let us first consider the goods, labour, and property markets. With perfect competition, firms' profits are zero. Normalising the price of good $x$ to one, workers employed in $j$ 's industrial sector receive wage $w_{j}$ equal to $a_{j}$. So do $j$ 's services' employees whoe provide $y$ for domestic customers, given intersectoral mobility. Then $j$ 's services for domestic customers carry price $p_{j}=a_{j} / b$. Specifically, $p_{R} / p_{P}=a_{R} / a_{P}>1$. This prediction, i.e. of a higher services price in the richer country, is typically referred to as the Balassa-Samuelson-Theorem (see Balassa (1964) and Samuelson (1964)).

The services price for cross-border shoppers has to exceed the services price for Poor's domestic customers $p_{P}$, since cross-border sellers have to be compensated for their cultural costs. Let one unit of cross-border services yield $p_{C}$ (to be determined below). Then perfect competition ensures that the respective employees' pay is tied to $w_{C}=b p_{C}$. Finally, note that perfect competition in the property markets drives Interior's rent down to $r_{j I}=d_{j}$ (whereas $r_{j B}$ has to be determined below). To sum up for later reference,

$$
w_{j}=a_{j}, \quad p_{j}=\frac{a_{j}}{b}, \quad w_{C}=b p_{C}, \quad r_{j I}=d_{j} .
$$

Throughout the text we assume that $\theta \in\left[0, p_{R}-p_{P}\right]$. Finally, we introduce, as an

\footnotetext{
${ }^{3}$ This timing is motivated by the observation that typically there is a substantial lapse of time between the political decision to go ahead with the integration project and the subsequent rise in taxes. So the location choice takes place after the political decision is made. We do not consider migration before Border citizens vote on the project. This decision structure captures the fact that individuals are simply born into one of the regions and that a region's native population has a 'head start' regarding local policy choices. For an alternative timing in which location choices are made before the regions go to the polls, see, for instance, Kessler/Luelfesmann (2005).
} 
auxiliary concept, 'adjusted income' $\omega_{j}$,

$$
\omega_{j}=\left\{\begin{array}{ll}
w_{C}-p_{P} & \text { if } j=P \\
w_{R}-\left(p_{C}+\theta\right) & \text { if } j=R
\end{array} .\right.
$$

for those involved in $j B$ 's cross-border selling and shopping, for short, cross-border interaction.

\subsection{Optimal Location, Employment, and Shopping}

Let us now turn to households' choices. Individuals decide whether to live in a country's Border or Interior and whether to become a cross-border seller (crossborder shopper) or not. These choices are very similar across $P k$ and $R k$. We can and, for the purpose of clarity, do focus on either one of the two. Given our belief that cross-border shopping affects the poor country more strongly, we first focus on the choices of Poor's natives, and all economic explanations refer to circumstances in Poor. Thus, the index $j$ used in our formulas represents $P$ for the best part of this section. Then, at the end of this subsection, we reinterpret our results from the perspective of Rich's natives, i.e., for $j=R$.

Consider a Poor Border native's employment options first. Firms may either be the 'cross-border type' (i.e., suppliers of services to cross-border shoppers), or the 'domestic type' (i.e., suppliers of services to domestic customers or domestic industry). Employment in cross-border type firms yields wage $w_{C}$ but entails cultural costs $z_{P B}$, whereas employment in domestic type firms pays $w_{P}$ without further costs. Next, consider potential locations that are Poor Border and Poor Interior. Continuing on in Poor Border requires $\left(1-\alpha_{P}\right) r_{P B}$ in rent as well as $t_{P B}$ in taxes. In contrast, emigrating to Poor Interior generates landlord receipts $\alpha_{P} r_{P B}$ from renting out the Poor Border plot that has been left behind, and entails migration costs $m_{P B}$ to get to, and paying $r_{P I}$ to live in, Poor Interior.

Since only Poor Border employers can offer cross-border services, there are three possible combinations of employment and residential status: action $(P B, P B)$ refers to remaining in Poor Border while refraining from cross-border selling, action $(P B, R B)$ refers to remaining in Poor Border and signing up with a cross-border type service supplier, while action $(P B, P I)$ refers to emigrating to Poor Interior. With prices, wages, taxes and 'adjusted income' defined in (2), (4) and (5), the corresponding individual utilities are

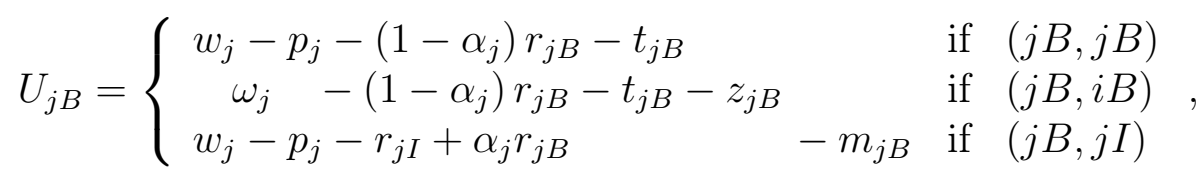

where, for notational convenience, individual index $h$ is (and will remain) suppressed.

Consider first a Poor Border native who chooses between $(P B, P B)$ and $(P B, R B)$. Cross-border selling offers a wage gain $\omega_{P}-\left(w_{P}-p_{P}\right)=w_{C}-w_{P}$. For the individual 
who is indifferent between these two alternatives, this wage gain is just offset by an equally large cultural handicap $z_{P B}$. Denote this threshold cultural cost by $\widetilde{z}_{P B}$. Poor Border natives with cultural costs below (greater than) $\widetilde{z}_{P B}$ may (will not) become cross-border sellers. For later reference,

$$
\widetilde{z}_{j B}=\omega_{j}-\left(w_{j}-p_{j}\right)=\left\{\begin{array}{ll}
w_{C}-w_{P} & \text { if } j=P \\
p_{R}-\left(p_{C}+\theta\right) & \text { if } j=R
\end{array} .\right.
$$

Consider next a Poor Border native who chooses between $(P B, P B)$ and $(P B, P I)$. Emigrating to Poor Interior permits rent and tax savings $\Delta r_{P}+t_{P B}$, where $\Delta r_{P}=$ $r_{P B}-r_{P I}$ defines the interregional rent differential. For the indifferent individual, these savings are just offset by migration costs $m_{P B}$. Denote threshold migration cost by $\widetilde{m}_{P B}$. Poor Border natives with migration costs $m_{P B}$ below (above) $\widetilde{m}_{P B}$ may (will clearly not) move to Poor Interior. Again, for later reference,

$$
\widetilde{m}_{j B}=\Delta r_{j}+t_{j B}
$$

Finally, consider a Poor Border native who chooses between $(P B, R B)$ and $(P B, P I)$. This individual shakes off cultural costs $z_{P B}$, cashes in on rent savings $\Delta r_{P}$, and even escapes Border taxation $t_{P B}$, all by moving to Poor Interior. However, she still has migration costs $m_{P B}$, and faces a wage reduction $w_{C}-w_{P}$. Comparing gains and losses, threshold cultural costs become $\widehat{z}_{P B}$, where $\widehat{z}_{P B} \equiv \omega_{P}-\left(w_{P}-p_{P}\right)-$ $\left(\Delta r_{P}+t_{P B}\right)+m_{P B}$. Any Poor Border native with cultural costs $z_{P B}$ below (greater than) $\widehat{z}_{P B}$ prefers cross-border selling to leaving for Poor Interior (leaving for Poor Interior to cross-border selling). For later purposes, and employing the definitions of $\widetilde{z}_{P B}$ and $\widetilde{m}_{P B}$ introduced in $(7)$ and $(8), \widehat{z}_{P B}$ can be rewritten as

$$
\widehat{z}_{j B}=\widetilde{z}_{j B}-\widetilde{m}_{j B}+m_{j B}
$$

Threshold costs $\widetilde{z}_{j B}, \widetilde{m}_{j B}$ and $\widehat{z}_{j B}$ are represented by the dashed indifference loci shown in Figure 1. These loci partition the support of the joint distribution function $F_{P}$ into three sets, such that individuals with characteristics in any given one of these sets pick the same optimal action. First, natives with both high $m_{P B}$ and high $z_{P B}$ (associated with set $(P B, P B)$ ) stay in Border yet stay out of Rich shoppers' way. Second, natives with low $z_{P B}$ both in absolute terms and relative to $m_{P B}$ (associated with $(P B, R B))$ stay in Poor Border to attend to Rich shoppers. And third, natives with high to intermediate $z_{P B}$ but low $m_{P B}$ (associated with $(P B, P I)$ ) are mobile enough to find it worthwhile to leave altogether.

Threshold cultural cost $\widetilde{z}_{P B}$ does not vary with $m_{P B}$, much as threshold migration cost $\widetilde{m}_{P B}$ does not vary with $z_{P B}$. In contrast, threshold cost $\widehat{z}_{P B}$ does depend on individual characteristics. The larger $m_{P B}$, the larger $\widehat{z}_{P B}$ needs to be. Intuitively, for a native initially indifferent between $(P B, R B)$ and $(P B, P I)$ a sudden drop in mobility costs increases her benefit from emigration. For her to remain indifferent, cultural costs also need to drop. Ultimately, this makes for the peculiarity that Poor 


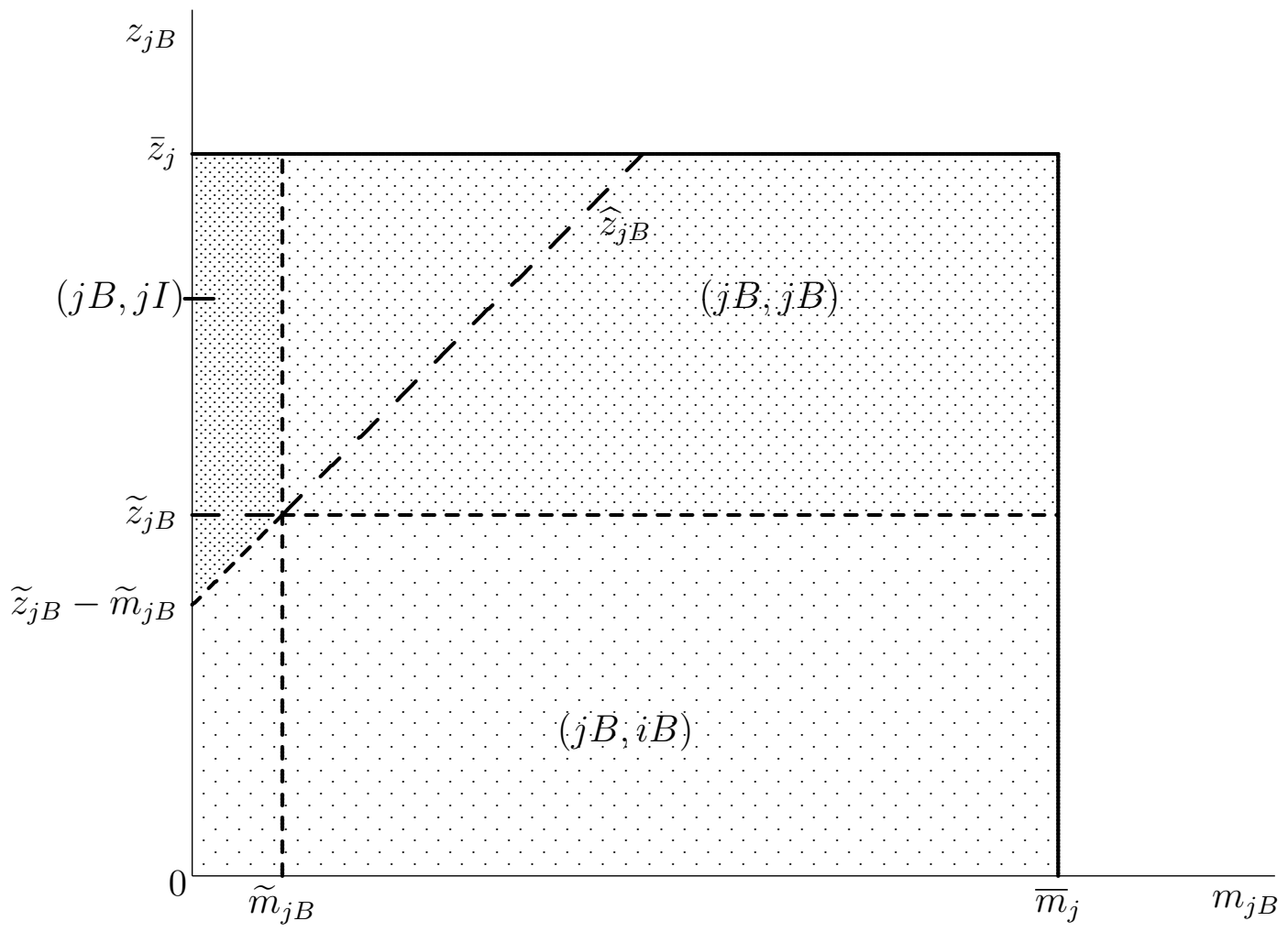

Figure 1: Border Natives By Employment and Eventual Location

Border natives whose cultural costs are rather low do not necessarily cross-border sell. Those in triangle $\left\{\left(m_{P B}, z_{P B}\right): m_{P B} \leq \widetilde{m}_{P B}, \widetilde{z}_{P B}-\widetilde{m}_{P B}+m_{P B} \leq z_{P B} \leq \widetilde{z}_{P B}\right\}$ find leaving even better.

Poor Interior natives avail themselves of three actions that closely parallel those open to Poor Border natives. A Poor Interior native may stay at home and thus abstain from cross-border interaction (i.e. $(P I, P I)$ ). Or, she may move to Poor Border to be able to cross-border sell (i.e. $(P I, R B)$ ). Or, she may move to Poor Border yet stay away from Rich shoppers (i.e. $(P I, P B)$ ). But note that this latter action is dominated by $(P I, P I)$. Intuitively, a Poor Interior native who moves to Poor Border without intending to cross-border sell does not benefit from, yet still has to pay the premium that others attach to, cross-border selling. Then the remaining two actions' utilities are

$$
U_{j I}=\left\{\begin{array}{lll}
w_{j}-p_{j}+\left(1-\alpha_{j}\right) r_{j B} & \text { if } & (j I, j I) \\
\omega_{j}+r_{j I}-\alpha_{j} r_{j B}-t_{j B}-m_{j I}-z_{j I} & \text { if } & (j I, i B)
\end{array}\right.
$$

On the one hand, a Poor Interior native benefits from the wage premium $w_{C}-w_{P}$ when moving to Poor Border. On the other hand, she must incur cultural costs $z_{P I}$, migration costs $m_{P I}, \Delta r_{P}$ on the extra in rent, and $t_{P B}$ on tax. For her to be indifferent between $(P I, P I)$ and $(P I, P B)$, her cultural cost must equal $\widetilde{z}_{P I}$, where $\widetilde{z}_{P I}=\omega_{P}-\left(w_{P}-p_{P}\right)-\left(\Delta r_{P}+t_{P B}\right)-m_{P I}$. Generally, a Poor Interior native resettles in Poor Border if, and only if, her cultural cost $z_{P I}$ falls short of threshold $\widetilde{z}_{P I}$. Poor Interior natives who head for the Border have the characteristics shown 


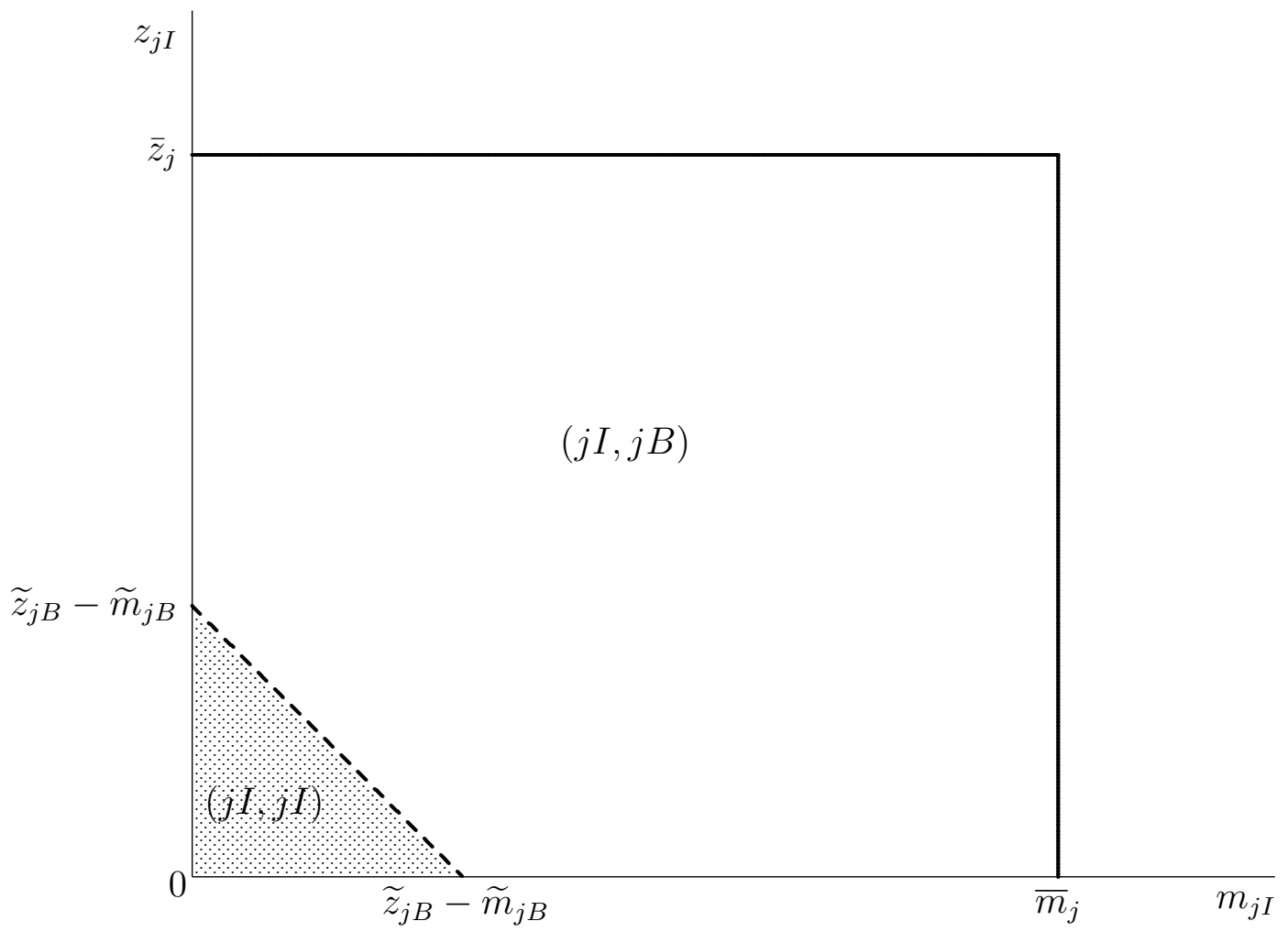

Figure 2: Interior Natives By Employment and Eventual Location

in Figure 2's shaded area. Making use of $\widetilde{z}_{P B}$ and $\widetilde{m}_{P B}$ (see (7) and (8)) one more time, threshold $\widetilde{z}_{P I}$ becomes

$$
\widetilde{z}_{j I}=\widetilde{z}_{j B}-\widetilde{m}_{j B}-m_{j I}
$$

To analyse the choices of Rich's natives, we just have to slightly modify the preceding argument. The counterparts of Poor's cross-border sellers are obviously Rich's cross-border shoppers. Only, the latter do not benefit from higher incomes, i.e., from wage $w_{C}$ instead of $w_{P}$, but instead from the lower costs of services net of transaction costs, i.e., from $p_{C}-\theta$ instead of price $p_{R}$. Otherwise, the benefits and costs from intra-country migration and cross-border services are qualitatively the same, and so, too, are the corresponding utilities of Rich natives (see (5), (6), and (10) with $j=R$ ). The resulting thresholds (7), (8) and (9) with $j=R$ separate Rich Border natives who continue to live in Border and buy services at home $(R B, R B)$ from those who remain in Border but cross-border shop $(R B, P B)$ and those who leave Border for Interior $(R B, R I)$. Similarly, threshold (11) shows which types of Rich Interior natives stay in Interior $(R I, R I)$ and which types leave for Border and cross-border shop $(R I, P B)$. Thus Figures 1 and 2 also illustrate the optimal choices of Rich natives, although the effects of border proximity are presumably smaller on their side of the border. For instance, the attraction of wage gains from cross-border selling for Poor Interior natives should be stronger than the attraction of the services price differential for Rich Interior natives. 


\subsection{Shopping and Migration Equilibrium}

A 'Cross-Border Shopping and Migration Equilibrium", or ShoMig Equilibrium, is the equilibrium obtained for the game's second stage. Specifically, ShoMig Equilibrium requires housing, goods and services markets to balance, with first stage policy variables $\left(\theta, t_{P B}, t_{R B}\right)$ given. Since in equilibrium regional housing supply equals regional housing demand, and since housing supply is fixed in the border regions, any region's immigrant inflow must also equal its emigrant outflow. Let $M_{j B}$ denote the number of those moving from $j B$ to $j I$, and let $M_{j I}$ denote the number of those moving from $j I$ to $j B$. By inspection of Figures 1 and $2, M_{j B}=\widetilde{m}_{j B}\left[\bar{z}_{j}-\widetilde{z}_{j B}+0.5 \widetilde{m}_{j B}\right]$ and $M_{j I}=0.5\left[\widetilde{z}_{j B}-\widetilde{m}_{j B}\right]^{2}$. Then Migration Equilibrium requires $M_{j B}=M_{j I}$, yielding

$$
\widetilde{m}_{j B}=\left[\widetilde{z}_{j B}\right]^{2} /\left(2 \bar{z}_{j}\right) \quad \Leftrightarrow \quad r_{j B}=d_{j}-t_{j B}+\left[\widetilde{z}_{j B}\right]^{2} /\left(2 \bar{z}_{j}\right),
$$

where the second equation follows from substituting (8) into the first equation. In equilibrium, migration ties Border's additional rent and tax burden (equal to $\widetilde{m}_{j B}$ ) to cross-border sellers' wage premium (equal to $\widetilde{z}_{P B}$ ) or cross-border shoppers' gains (equal to $\widetilde{z}_{R B}$ ).

Next, let $Y_{P}$ denote Poor Border's aggregate supply of, and $Y_{R}$ Rich Border's aggregate demand for, cross-border services. Cross-border sellers include new arrivals in Poor Border, $M_{P I}$, as well as indigenous Poor Border sellers, denoted $C_{P B}$. Likewise, cross-border shoppers include new arrivals from Rich Interior, $M_{R I}$, as well as indigenous Rich Border shoppers, denoted $C_{R B}$. Then Shopping Equilibrium requires $Y_{P}=Y_{R}$, or

$$
b\left(C_{P B}+M_{P I}\right)=C_{R B}+M_{R I},
$$

with $Y$ denoting equilibrium services consumption, or "cross-border sales". (We reserve the convenient term 'sales' for $Y$, rather than for the frequently implied $p_{C} Y$.)

Formally, a ShoMig Equilibrium is a list of prices $\left(p_{C}, r_{P B}, r_{R B}\right)$ and corresponding quantities $\left(Y, C_{j B}, M_{j B}, M_{j I}\right)$ that satisfy the three equilibrium conditions set out in (12) and (13) - for a given policy set $\left(\theta, t_{P B}, t_{R B}\right)$, given mobility and cultural cost parameters $\left(\bar{m}_{P}, \bar{m}_{R}, \bar{z}_{P}, \bar{z}_{R}\right)$, and a given regime of housing property rights $\left(\alpha_{P}, \alpha_{R}\right)$. ShoMig Equilibrium's basic properties are detailed in

\section{Proposition 1: ShoMig Equilibrium}

(i) ShoMig Equilibrium exists.

(ii) ShoMigEquilibrium is unique.

(iii) ShoMig Equilibrium's prices and quantities are functions of transaction costs $\theta$ and of migration cost parameters $\bar{m}_{P}$ and $\bar{m}_{R}$.

(iv) ShoMig Equilibrium's prices and quantities are unaffected by any switch in the housing ownership regime parameter $\alpha_{j}$. 
Proofs of parts (i), (ii) and (iii) are in the Appendix, while part (iv) is explained below. Parts (i) and (ii) just serve as a technical prerequisite for our further analysis. Part (iii) states that, in particular, local politics' choice of transaction costs in the first stage affects equilibrium prices and quantities. By contrast, part (iv) points out, more surprisingly, that the housing ownership regime is irrelevant to ShoMig Equilibrium. The intuition for this irrelevance is straightforward. For individual choices, opportunity costs matter, but these opportunity costs depend on rent differentials and not on who pays and who receives rents. For instance, consider our comparison of alternatives $(P B, P B)$ and $(P B, P I)$ above. With native ownership, emigration yields $r_{P B}$ that is received from Poor Border but requires $r_{P I}$ to be paid in Poor Interior. With absentee ownership, emigration releases $r_{P B}$ but also requires $r_{P I}$. For both regimes, the resulting rent differential, and hence migration cost threshold $\widetilde{m}_{P B}$, is the same. More generally, thresholds $\widetilde{z}_{j B}, \widetilde{m}_{j B}, \widehat{z}_{j B}$ and $\widetilde{z}_{j I}$ do not depend on the ownership regime and then neither does the ShoMig Equilibrium.

\section{ShoMig Equilibrium and Integration}

This section explores ShoMig Equilibrium further. Its properties identified in this section subsequently enter the following section's investigation into whether a given integration project appeals to rational voters. Proposition 2 analyses how the reduction in transaction costs $\theta$ induced by an integration project affects the ShoMig Equilibrium. Proposition 3 discusses the extent to which the integration project's impact varies with changes in intra-country mobility, as captured by parameters $\bar{m}_{P}$ and $\bar{m}_{R}$. And Proposition 4 addresses the effects of a given integration project on welfare.

\section{Proposition 2: ShoMig Equilibrium and the Integration Project}

(i) Services price $p_{C}$, sales $Y$, wage $w_{C}$, and Border rents $r_{P B}$ and $r_{R B}$ are decreasing, while transaction cost inclusive services price $p_{C}+\theta$ is increasing, in $\theta$.

(ii) The number of sellers and shoppers native to Border, $C_{P B}$ and $C_{R B}$, as well as the number of sellers and shoppers native to Interior, $M_{P I}$ and $M_{R I}$, are decreasing in transaction costs $\theta$.

(iii) Let $\theta$ be given. Then services price $p_{C}$, sales $Y$, and wage $w_{C}$ are constant in taxes $t_{P B}$ and $t_{R B}$. In contrast, Border rents $r_{P B}$ and $r_{R B}$ are decreasing in respective taxes $t_{P B}$ and $t_{R B}$.

While we delegate the formal proof to the Appendix, the underlying economics seem intuitive enough. Suppose transaction $\operatorname{costs} \theta$ fall. Then more Rich Border natives will want to cross-border shop. While additional demand pushes up crossborder services price $p_{C}$, this subsequent increase is not sufficient to offset the initial reduction in transaction costs. That is, transaction cost inclusive of services price 
$\left(p_{C}+\theta\right)$ also falls .4 Moreover, the increase in services' price $p_{C}$ raises cross-border sellers' wage $w_{C}$, too. In response, not only will more Poor Border natives want to cross-border sell, but larger numbers of Poor Interior natives will be eager to join them. Similarly (though presumably on a smaller scale), additional Rich Interior natives move into Rich Border in order to exploit those new opportunities to shop.

As the migration flows' responses show, allowing for within-country migration ultimately reinforces the boom in cross-border interaction triggered by the initial drop in transaction costs. This boom is only slowed down by a rise in Border rents subsequent to the increase in migration flows. Experimenting with Figures 1 and 2 illustrates the impact of lower transaction $\operatorname{costs} \theta$ on borderland's population composition. As $\theta$ falls, the $\widetilde{z}_{j B}$-locus, the $\widehat{z}_{j B}$-locus and the $\widetilde{z}_{j I^{-}}$locus all shift upward, while the $\widetilde{m}_{j B}$-locus shifts to the right. In combination, these shifts produce the changes predicted for household allocation.

The equilibrium service price is unaffected by tax levels $t_{P B}$ and $t_{R B}$, and hence by a change in the magnitude of project costs, and so, too, are equilibrium quantities. Any change in tax level $t_{j B}$ immediately, and wholly, capitalises into Border rent $r_{j B}$. However, note that project costs and taxes do affect the integration project's distribution of gains and losses. Project costs and attendant taxes turn out to be important for individuals' decisions at the polls (see section 5).

Now, ShoMig Equilibrium depends not just on inter-country integration, as captured by transaction costs $\theta$, it also depends on intra-country integration, as reflected by mobility parameter $\bar{m}_{j}$.

\section{Proposition 3: ShoMig Equilibrium and Interregional Mobility}

(i) Services price $p_{C}$, wage $w_{C}$ and rent $r_{P B}$ are increasing (decreasing) in the mobility parameter $\bar{m}_{P}\left(\bar{m}_{R}\right)$, while rent $r_{R B}$ is decreasing (increasing) in $\bar{m}_{P}\left(\bar{m}_{R}\right)$. Sales $Y$ are decreasing in either of the mobility parameters $\bar{m}_{P}$ and $\bar{m}_{R}$.

(ii) The number of sellers native to Poor Border $C_{P B}$ (shoppers native to Rich Border $C_{R B}$ ) is increasing, while the number of sellers native to Poor Interior $M_{P I}$ (shoppers native to Rich Interior $M_{R I}$ ) is decreasing in mobility parameter $\bar{m}_{P}$ $\left(\bar{m}_{R}\right)$.

(iii) The numbers of shoppers native to Rich Border $C_{R B}$ or Rich Interior $M_{R I}$ (sellers native to Poor Border $C_{P B}$ or Poor Interior $M_{P I}$ ) are decreasing in mobility parameter $\bar{m}_{P}\left(\bar{m}_{R}\right)$.

We again provide the proof in the Appendix and instead focus here on the underlying intuition. Suppose mobility parameter $\bar{m}_{P}$ falls, representing an increase in Poor households' mobility between Poor Interior and Poor Border. (Discussion of a fall in $\bar{m}_{R}$ is similar and therefore dropped.) More Poor Interior natives will dis-

\footnotetext{
${ }^{4} \mathrm{~A}$ decline in transaction $\operatorname{costs} \theta$ is similar to a fall in tariffs. The latter, too, drives producer prices up, but this rise cannot overcompensate the initial cut in tariffs, so that consumer prices (i.e., producer prices plus tariffs) also decrease.
} 
cover that their individual migration cost is sufficiently low enough to make entering Poor Border's cross-border services sector worthwhile. Cross-border services' supply expands, cross-border sales $Y$ rise subsequently, and cross-border services price $p_{C}$ and wage $w_{C}$ correspondingly fall. While lower wage $w_{C}$ translates into lower Poor Border rent $r_{P B}$, lower price $p_{C}$ - that makes living in Rich Border more attractive - translates into higher Rich Border rent $r_{R B}$ (Proposition 3, Part (i)).

Straightforward changes in prices and sales conceal important composition effects. The fall in the price of services, brought about by the extra influx of Poor Interior natives, tends to crowd Poor Border natives out of cross-border selling (Proposition 3, Part (ii)). Given that overall sales increase, the number of Poor Border natives crowded out must surely be smaller than that of Poor Interior natives crowding in. This composition effect has no parallel in Rich. The reduction in the price of cross-border services unambiguously attracts extra cross-border shoppers from Rich Border and Rich Interior (Proposition 3, Part (iii)).

Finally, we turn to the regional integration project's normative implications. We show how its evaluation depends on the project parameters $\underline{\theta}, t_{P B}$ and $t_{R B}$, on the initial transaction cost $\bar{\theta}$, and on intra-country mobility parameters $\bar{m}_{P}$ and $\bar{m}_{R}$. This analysis later enables us to point out the circumstances under which the very same forces that improve the project's potential aggregate gains also undermine its political acceptance.

Following a simple utilitarian approach, we focus on the aggregate willingnessto-pay for the project across all individuals in order to assess the project's welfare effects. Let $U\left(m_{j k}, z_{j k}, \theta, t_{j k}\right)$ indicate the ShoMig equilibrium's utility level of an individual native to $j k$, who is endowed with individual characteristics $\left(m_{j k}, z_{j k}\right)$, and faces policy parameters $\left(\theta, t_{j k}\right)$. Then $U\left(m_{j k}, z_{j k}, \underline{\theta}, t_{j k}\right)$ and $U\left(m_{j k}, z_{j k}, \bar{\theta}, 0\right)$ denote individual utility levels with, and without, the integration project being implemented. Since utility is measured in terms of the numeraire good $x$ (see (3)), individual willingness-to-pay for the project in real terms, that can be positive or negative, amounts to $\Delta U\left(m_{j k}, z_{j k}, \bar{\theta}, \underline{\theta}, t_{j k}\right)=U\left(m_{j k}, z_{j k}, \underline{\theta}, t_{j k}\right)-U\left(m_{j k}, z_{j k}, \bar{\theta}, 0\right)$. Then aggregate willingness to pay $(A W T P)$ is

$$
A W T P=\sum_{j \in\{P, R\}} \frac{N_{j}}{\bar{m}_{j} \bar{z}_{j}} \sum_{k \in\{B, I\}}\left(\int_{0}^{\bar{m}_{j}} \int_{0}^{\bar{z}_{j}} \Delta U\left(m_{j k}, z_{j k}, \bar{\theta}, \underline{\theta}, t_{j k}\right) d z_{j k} d m_{j k}\right)
$$

To highlight the project's impact, we assume that, initially, border regions are not integrated at all:

Assumption 1: $\bar{\theta}=p_{R}-p_{P}$.

From a stylised perspective, this must be a reasonable representation of the preintegration state. Initially, no one finds cross-border selling or shopping worthwhile, i.e., $\widetilde{z}_{j B}=0$, and no Interior native moves towards the border, i.e., $\widetilde{m}_{j B}=0$. Border rents settle at respective levels of Interior rents: $r_{j B}(\bar{\theta})=d_{j}=r_{j I}$, given 


\begin{tabular}{|c|l||c|r|}
\hline Action & Group Size & Real Gain & Redist. Gain \\
\hline \hline$(P B, R B)$ & $C_{P B}$ & $w_{C}-w_{P}-t_{P B}-z_{P B}$ & $-\left(1-\alpha_{P}\right) \Delta r_{P}$ \\
\hline$(P B, P I)$ & $M_{P B}$ & $-m_{P B}$ & $\alpha_{P} \Delta r_{P}$ \\
\hline$(P B, P B)$ & $N_{P}-\left(C_{P B}+M_{P B}\right)$ & $-t_{P B}$ & $-\left(1-\alpha_{P}\right) \Delta r_{P}$ \\
\hline$(P I, P B)$ & $M_{P I}$ & $w_{C}-w_{P}-t_{P B}-z_{P I}-m_{P I}$ & $-\alpha_{P} \Delta r_{P}$ \\
\hline$(P I, P I)$ & $N_{P}-M_{P I}$ & 0 & $\left(1-\alpha_{P}\right) \Delta r_{P}$ \\
\hline \hline$(R B, P B)$ & $C_{R B}$ & $p_{R}-p_{C}-\underline{\theta}-t_{R B}-z_{R B}$ & $-\left(1-\alpha_{R}\right) \Delta r_{R}$ \\
\hline$(R B, R I)$ & $M_{R B}$ & $-\alpha_{R} \Delta r_{R}$ \\
\hline$(R B, R B)$ & $N_{R}-\left(C_{R B}+M_{R B}\right)$ & $-t_{R B}$ & $-\left(1-\alpha_{R}\right) \Delta r_{R}$ \\
\hline$(R I, R B)$ & $M_{R I}$ & $p_{R}-p_{C}-\underline{\theta}-t_{R B}-z_{R I}-m_{R I}$ & $-\alpha_{R} \Delta r_{R}$ \\
\hline$(R I, R I)$ & $N_{R}-M_{R I}$ & 0 & $\left(1-\alpha_{R}\right) \Delta r_{R}$ \\
\hline
\end{tabular}

Table 1: Welfare Effects of Integration by Group Affiliation

(12). Consequently, with native ownership, a Border native's utility is equal to an Interior native's utility. For later reference, a Poor Border native's utility is

$$
U\left(m_{j k}, z_{j k}, \bar{\theta}, 0\right)=w_{j}-p_{j}-\left(1-\alpha_{j}\right) d_{j}
$$

With integration, individual utilities become those given in (6) and (10), evaluated at the levels of the endogenous variables obtained in the ShoMig equilibrium for $\theta=$ $\underline{\theta}$. We distinguish ten distinct groups of individuals that emerge under integration. Table 1 lists these by the actions that characterize them. Moreover, for each group, Table 1 gives the change in utility that any of its members enjoys, or incurs to endure, under integration. This utility change, or individual willingness-to-pay $\Delta U$, may be decomposed into two components: first, there are those purely 'redistributive rent gains and losses", which are immediately offset by someone else's losses and gains, given that landlords are part of the model. These changes, shown in column 4 of Table 1, are neutral at the aggregate level. And, second, there are those 'real gains and losses", which are not directly offset. These comprise changes in wage income, cross-border services price, and migration and cultural costs, as shown in Table 1's column 3. It is these latter changes that determine aggregate willingness-to-pay.

Proposition 4 now reviews how changes in policy or mobility characteristics affect aggregate willingness-to-pay for the integration project.

\section{Proposition 4: Aggregate Willingness-To-Pay (AWTP)}

(i) AWTP is decreasing in taxes $t_{P B}$ and $t_{R B}$, is positive if these are sufficiently small, and is negative if taxes satisfy $N_{P} t_{P B}+N_{R} t_{R B}=N_{R}(\bar{\theta}-\underline{\theta})$. 
(ii) AWTP is decreasing in the transaction costs $\underline{\theta}$ obtained when the integration project is implemented. Moreover, AWTP declines if the initial transaction costs $\bar{\theta}$ decrease.

(iii) AWTP is decreasing in migration cost parameters $\bar{m}_{P}$ and $\bar{m}_{R}$.

We again delegate the proof to the appendix and instead focus on the intuition. The proposition's first part addresses variations in taxes, reflecting variations in project costs at given transaction cost parameters $\bar{\theta}$ and $\underline{\theta}$. To understand this part, first note that, since there are no market distortions, for given individual characteristics and policy individuals sort and shop efficiently. Since markets are efficient, any cut in transaction costs in itself implies aggregate gains and thus a positive $A W T P$. Considering projects costs $e_{P}$ and $e_{R}, A W T P$ is positive as long as the resultant taxes $t_{P B}$ and $t_{R B}$ are zero or sufficiently close to zero. Obviously, larger costs, and thus taxes, are associated with smaller aggregate project gain. Ultimately, some projects are simply too costly to be viable. Should a project's total tax burden, i.e., $N_{P} t_{P B}+N_{R} t_{R B}$, even exceed the aggregate reduction of transaction costs to be had if all Rich Border residents cross-border-shop, i.e., $N_{R}(\bar{\theta}-\underline{\theta})$, then this project would definitely reduce welfare.

The proposition's second part analyses the effects of variations in transaction costs for given taxes, assuming that the levels $\bar{\theta}$ and $\underline{\theta}$ are independent of one another. Naturally, the larger the project-induced cut in transaction costs $\bar{\theta}-\underline{\theta}$, the larger is $A W T P$. A larger cut not only generates a greater benefit per unit of cross-border services traded but also causes the numbers of those trading in Poor's services to expand further. Thus $A W T P$ is decreasing in transaction costs $\underline{\theta}$. Moreover, AWTP is smaller if initial transaction costs $\bar{\theta}$ are lower.

The proposition's third part discusses the effect of variations in mobility parameters $\bar{m}_{P}$ and $\bar{m}_{R}$. Suppose that $\bar{m}_{P}$ drops, meaning that mobility in Poor rises. Higher mobility crowds Poor Border natives out of the cross-border services sector, crowds in Poor Interior natives, and increases total cross-border sales, as shown earlier in Proposition 3. Clearly, larger cross-border sales enhance trade gains. But note that the change in cross-border sellers' composition also promotes trade gains. The cultural and migration costs of Poor Interior natives who now enter are actually lower than the cultural costs of those Poor Border natives who are now driven out. ${ }^{5}$ Similarly, a decline in $\bar{m}_{R}$ positively affects total cross-border sales and the composition of cross-border shoppers, albeit probably on a smaller scale. Put differently, more mobile societies are more effective at sorting into the border's proximity those who require the lowest compensation for interacting with those from the border's other side. These therefore benefit more strongly from a cut in transaction costs.

\footnotetext{
${ }^{5}$ And even those who leave Poor Border for Interior do that at lower perceived migration costs. Note that, in our analysis, we have also taken account of the migration costs that burden those Border natives in Rich and Poor who move to Interior.
} 


\section{Voting on the Regional Integration Project}

Having analysed some important properties of the ShoMig Equilibrium for exogenously given policy, we can now proceed to investigate the outcome of the referendum on the regional integration project at the first stage and the normative performance of the voting process. We start by analysing the political preferences of the different types of citizens. Then proposition 5 specifies the circumstances under which the $A W T P$ of any politically approved project is indeed positive. Proposition 6 discusses the impact of intra-country mobility on voting. And propositions 7 and 8 finally shed some light on the relationship between regional and (inter-)national policies.

\subsection{Political Preferences}

At the game's first stage, Border natives vote on the integration project $\left(\underline{\theta}, t_{P B}, t_{R B}\right)$. Natives to $j B$ vote on $\left(\underline{\theta}, t_{j B}\right)$. Border region polls are separate but simultaneous. Recall that citizens are fully rational. In particular, they take into account the impact of the political outcome on the succeeding location and occupation choices when they make their decisions at the polls. ${ }^{6}$ Any voter's approval is solely governed by whether the utility attained with the project implemented exceeds the utility without it. So voters compare $U\left(m_{j k}, z_{j k}, \underline{\theta}, t_{j k}\right)$, obtained in ShoMig Equilibrium for $\underline{\theta}$ and $t_{j k}$, with $U\left(m_{j k}, z_{j k}, \bar{\theta}, 0\right)$, obtained in ShoMig Equilibrium for $\bar{\theta}$. We divide voters into three groups, depending on which action in $\{(j B, j B),(j B, j I),(j B, i B)\}$ they take when the project is implemented. This division is independent of the housing ownership regime that is in place (Proposition 1, Part (iv)).

Consider those who would choose $(j B, j B)$, i.e., to stay in Border, but abstain from cross-border selling or shopping. Far from reaping any of the integration project's prospective benefits, these individuals would be exposed to all of its disadvantages. Not only would they have to contribute to the project's funding by having to pay $\operatorname{tax} t_{j B}$. They would also even have to incur increased rent $r_{j B}>d_{j}=r_{j I}$ if their dwelling belonged to an Interior landlord. That is, those who choose $(j B, j B)$ receive payoff $w_{j}-p_{j}-\left(1-\alpha_{j}\right) d_{j}$ without, and the unambiguously smaller payoff $w_{j}-p_{j}-t_{j B}-\left(1-\alpha_{j}\right) r_{j B}$ with, the project's implementation (cf. (6) and (15)). Anticipating this, they vote against the project, irrespective of the ownership regime in place.

Next, consider those who would opt for $(j B, j I)$, i.e. for leaving Border. These individuals receive $w_{j}-p_{j}-\left(1-\alpha_{j}\right) d_{j}$ without the project's implementation, as opposed to $w_{j}-p_{j}-d_{j}+\alpha_{j} r_{j B}-m_{j B}$ with it, as (6) and (10) show. The latter exceeds the former whenever the individual's migration costs $m_{P B}$ fall short of the 'migration cost voting threshold' $\widetilde{m}_{j B}^{V}=\alpha_{j} \Delta r_{j}$, or equivalently, by virtue of (8),

\footnotetext{
${ }^{6}$ This assumption seems to be empirically backed. According to Epple et al.'s (2001) analysis of majority rule and Tiebout sorting, models based on sophisticated voting behaviour fit the data better than those based on myopic voting behaviour.
} 
whenever $m_{P B}$ falls short of

$$
\widetilde{m}_{j B}^{V}=\alpha\left(\widetilde{m}_{j B}-t_{j B}\right)
$$

With absentee ownership (i.e. $\alpha=0$ ), threshold $\widetilde{m}_{j B}^{V}$ simply is zero. Those who would leave $j B$ upon implementation of the project equivocally oppose it, since, compared to the situation where the project is not implemented, here they have to bear migration costs without receiving any benefits. With native ownership (i.e. $\alpha=1$ ), by contrast, threshold $\widetilde{m}_{j B}^{V}$ comes to match the rent differential $\Delta r_{j}>0$, since those who move to Interior can gain from renting out their property in Border. Those whose migration costs are $m_{j B}<\Delta r_{j}$ support the project, whereas those whose costs are $m_{j B} \geq \Delta r_{j}$ turn out against it. Intuitively, native ownership makes the project palatable to those who can easily cash in on the rent differential. This is reminiscent of Wildasin $(1986,90)$.

Finally, consider those who would choose $(j B, i B)$, i.e. to stay in Border and to engage in cross-border selling or shopping. These receive $w_{j}-p_{j}-\left(1-\alpha_{j}\right) d_{j}$ without integration, as opposed to $\omega_{j}-\left(1-\alpha_{j}\right) r_{j B}-t_{j B}-z_{j B}$ with it. The latter payoff exceeds the former if, and only if, the individual's cultural cost falls short of 'cultural cost voting threshold' $\widetilde{z}_{j B}^{V}=\omega_{j}-\left(w_{j}-p_{j}\right)-\left(1-\alpha_{j}\right) \Delta r_{j}-t_{j B}$. Alternatively, by (7),

$$
\widetilde{z}_{j B}^{V}=\widetilde{z}_{j B}-\left(1-\alpha_{j}\right) \Delta r_{j}-t_{j B}= \begin{cases}\widetilde{z}_{j B}-\widetilde{m}_{j B} & \text { if } \alpha_{j}=0 \\ \widetilde{z}_{j B}-t_{j B} & \text { if } \alpha_{j}=1\end{cases}
$$

With native ownership, prospective cross-border traders vote in favour of the project if, and only if, the cross-border sellers' or shoppers' gain from the project $\omega_{j}-\left(w_{j}-\right.$ $p_{j}$ ), which equals $\widetilde{z}_{j B}$, is not offset entirely by the cultural cost and the fiscal burden. Approval recedes even further with absentee ownership. Now only those who find its gain large enough to also cover the implied rise in border rent endorse integration.

Figure 3 illustrates voting thresholds $\widetilde{m}_{j B}^{V}$ and $\widetilde{z}_{j B}^{V}$ for both housing ownership regimes. The heavily shaded area contains supporters' characteristics with absentee ownership. Additional, and more lightly, shaded areas add the characteristics of those who join supporters' ranks under native ownership. Approval is unambiguously greater with native ownership, as is obvious from Figure 3. Supporters' share in the total of votes cast in $j B, V_{j B}$, becomes $^{7}$

$$
V_{j B}=\left[\bar{m}_{j} \widetilde{z}_{j B}^{V}+\widetilde{m}_{j B}^{V}\left(\bar{z}_{j}-\widetilde{z}_{j B}^{V}\right)\right] \frac{1}{\bar{m}_{j} \bar{z}_{j}}
$$

Figure 3 also shows that, for strictly positive taxes, not all cross-border shoppers or sellers $C_{j B}$ vote for the project $V_{j B}$. Individuals might benefit from cross-border interaction once the project is implemented, and taxes and higher rents have to be paid anyway and are thus sunk. But they might, nevertheless, be better off in the

\footnotetext{
${ }^{7}$ We focus on 'interior' solutions; that is, solutions in which (i) $0<\widetilde{z}_{P B}^{V}<\bar{z}_{P}$ and - for the case where $\alpha=1-\left(\right.$ ii) $0<\widetilde{m}_{P B}^{V}<\bar{m}_{P}$ result.
} 


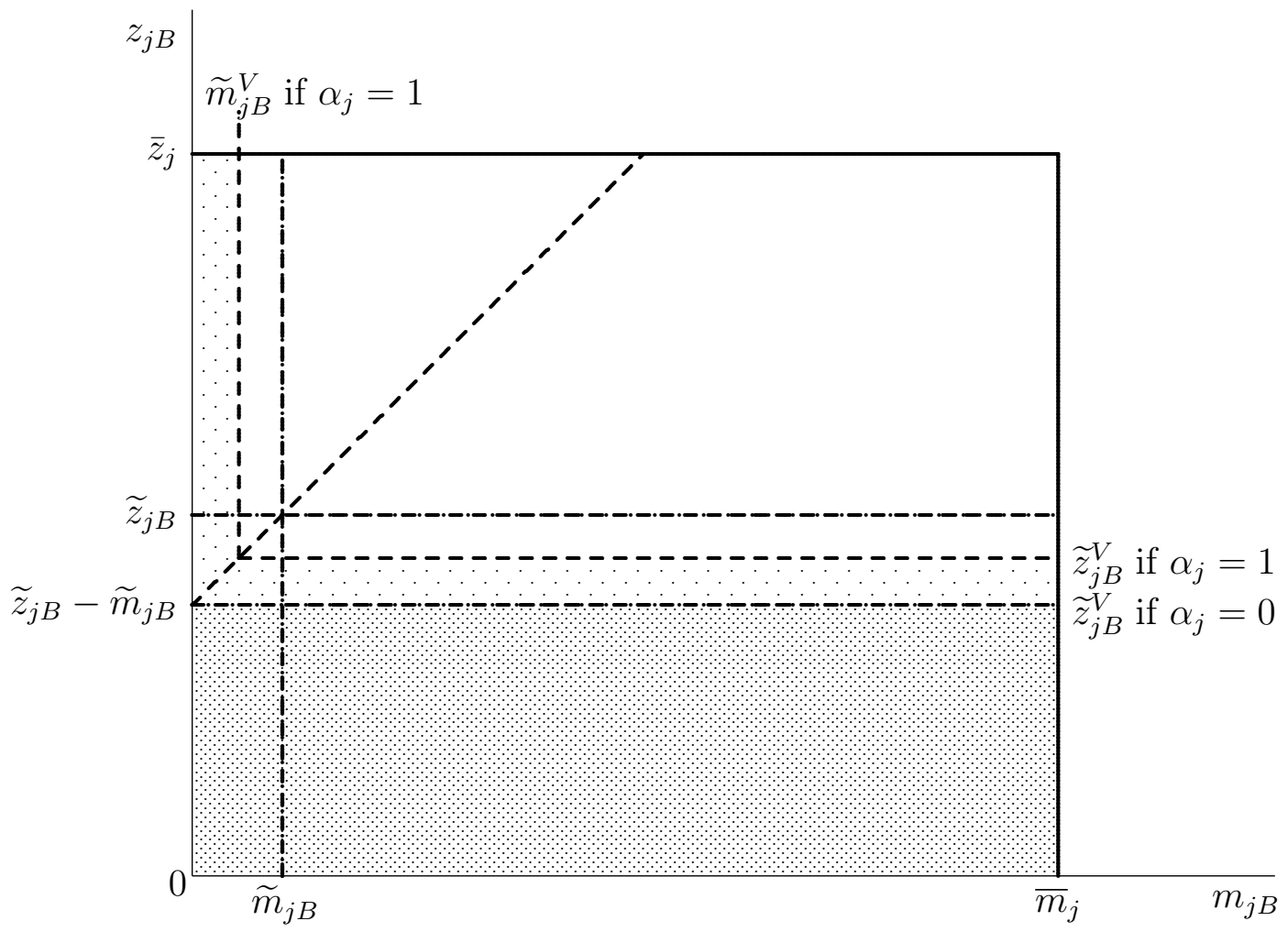

Figure 3: Housing Ownership Regime and Political Support

first place without integration and its drawbacks. So individuals do not reveal that they have supported the project ex ante just because they embrace the project's opportunities ex post (whatever the ownership regime).

\subsection{Majorities, Welfare, and Mobility}

Project approval requires a majority of votes in both border regions, i.e., $V_{P B}>0.5$ and $V_{R B}>0.5$. AWTP is certainly not positive for every project, as Proposition 4, Part (i), shows. When can we be certain that the AWTP is positive for an approved project? The following proposition shows that absentee ownership is a sufficient condition.

\section{Proposition 5: Voting and Aggregate Willingness to Pay}

With absentee ownership $\left(\alpha_{j}=0\right)$, every approved project $\left(\underline{\theta}, t_{P B}, t_{R B}\right)$ is strictly welfare enhancing, meaning that, for every project approved, AWTP is positive.

We again provide the formal proof in the Appendix and now discuss this statement rather informally. To understand our conclusion, recall that $\widetilde{z}_{j B}^{V}$ denotes the cultural costs of the 'marginal' citizens who are just indifferent between carrying out and not carrying out the project. So the project gain of a cross-border seller or shopper with cultural costs $z_{j B}<\widetilde{z}_{j B}^{V}$ is exactly the difference $\widetilde{z}_{j B}^{V}-z_{j B_{i}}$. Now imagine that all individuals with $z_{j B}>\widetilde{z}_{j B}^{V}$ would also become cross-border sellers or shoppers, with 
individual loss equal to $z_{j B}-\widetilde{z}_{j B}^{V}$. Even in this case, since (i) individual cultural costs are symmetrically distributed around the critical value $\widetilde{z}_{j B}^{V}$ and (ii) $z_{j B}<\widetilde{z}_{j B}^{V}$ holds for more than $50 \%$ of the citizens if the project wins at the polls, for every opponent of the project, there is a citizen whose individual benefits are at least as high as the opponent's loss. And, in fact, opponents can further limit their losses, either to $\Delta r_{j}+t_{j B}$ by avoiding cross-border shopping and selling (and staying in the Borders) or to even less than this by moving to the Interior. Finally, note that Interior natives cannot possibly lose from the integration project. After all, the project does not just raise Interior landlords' rent incomes received from Border residents. It also provides them with the extra, and potentially interesting, option of moving into the Border region. Consequently, $A W T P$ is positive if the project is approved by a majority.

This conclusion does not necessarily hold with native ownership. The reason is that, in this case, the project is also supported by Border natives who will move to Interior and cash in on the rent differential. Since this rent gain is purely redistributive, in a sense, voting outcome overstates real project gains. ${ }^{8}$

Note that Proposition 5 cannot be reversed. A project with a positive $A W T P$ need not be capable of securing approval. For example, suppose that there is absentee ownership, and consider a project that divides the electorate on both sides of the border evenly into supporters and opponents. Then that project's AWTP must be positive, given the previous paragraph's discussion. Now, a small reduction in the project's effectiveness, i.e. a small increase in $\underline{\theta}$, causes the project to be defeated at the polls even though it would still improve welfare. In short, positive $A W T P$ and project approval need not coincide.

One might hope that greater intra-country mobility could contribute to overcoming the political impasse. After all, since greater mobility induces more effective sorting and thus raises $A W T P$ (see Proposition 4, Part (iii)), it might also promote the project's political acceptance. Proposition 6 cautions against this assertion.

\section{Proposition 6: Voting and Mobility}

(i) With absentee ownership $\left(\alpha_{j}=0\right)$, the share of supporters $V_{j B}$ is increasing in the mobility parameter $\bar{m}_{j}$.

(ii) With native ownership $\left(\alpha_{j}=1\right)$, the share of supporters $V_{j B}$ is decreasing (increasing) in the mobility parameter $\bar{m}_{j}$ if the project's fiscal burden $t_{j B}$ is sufficiently small (large).

(iii) Whichever the housing ownership regime, the share of supporters $V_{P B}\left(V_{R B}\right)$ is decreasing in the neighbouring country's mobility parameter $\bar{m}_{R}\left(\bar{m}_{P}\right)$.

The first part of Proposition 6 argues that, with absentee ownership, greater mo-

\footnotetext{
${ }^{8}$ Proposition 5 also requires that the joint density function is not substantially skewed towards types of low cultural costs. However, the assumption of a uniform distribution seems to be a natural starting point, given that data on cultural and migration costs are hard to obtain.
} 
bility (i.e. a lower $\bar{m}_{j}$ ) actually generates less support for the project among border natives. An integration project attracts Interior natives. In Poor, for instance, Interior immigrants add to existing cross-border sellers' numbers, expanding the service's supply and driving down its price. This translates into smaller income gains that voters can expect from the integration project in the first place. In addition, the inflow additionally pushes rents up. The greater mobility, the greater this inflow of Interior natives, and the larger the negative impact of these immigrants on the project gains of the Border natives. Thus, mobility lowers political support for the project.

This also holds for Rich. Here, too, greater mobility means more Interior natives moving to Border to cross-border shop, thus driving up both the cross-border services price and Rich Border rent. Again, by reducing voters' project benefits, this inflow comes at the expense of local support. Again political support for the project is undermined. This political-economic impact of mobility has profound implications. Consider a project with a positive $A W T P$ that is approved of in a less mobile society. This very project could fail at the polls in the more mobile society, even though its $A W T P$ would be even higher (Proposition 4, Part (iii)). In this sense, greater mobility, while raising potential welfare gains, also makes realising these potential gains less likely.

With native ownership this ambiguity disappears, though only for sufficiently low project costs. Cross-border traders are no longer alone in weighing up the project. Those who would emigrate if the project were implemented now also consider supporting it. Suppose, for the moment, that the project is free, i.e., suppose $t_{j B}=0$. In this case $\widetilde{z}_{j B}^{V}=\widetilde{z}_{j B}$ by (16), and $\widetilde{m}_{j B}^{V}=\widetilde{m}_{j B}$ by (16). All individuals who are involved in cross-border services trade, or who leave Border for Interior, benefit from the project, either by trade gains or by cashing in on rent differentials. The number of supporters coincides with the number of those who ultimately engage in crossborder trade upon project completion. (See Figure 3, and recall that Border natives who emigrate are replaced by Interior natives who cross-border trade.) This number is thus $Y$ in Rich and $Y / b$ in Poor. Since sales $Y$ are decreasing in $\bar{m}_{j}$ (Proposition 3 , Part (i)), so too are supporters' ranks. In fact, supporters' ranks are decreasing in $\bar{m}_{j}$ even if taxes $t_{j B}$ are strictly positive, as long as taxes remain sufficiently small.

Matters are different, however, if taxes are large. A rising tax burden does not alter the cross-border services' sales and price (Proposition 2, Part (iii)), but it capitalizes into lower Border rent and, hence, a diminished interregional rent differential (see (8) and (12)). As $t_{j B}$ keeps rising, this differential vanishes, eventually resulting in $\Delta r_{j}=0$. With no rent differential left, a Border native who leaves for Interior and rents her property can no longer benefit from the integration project. Voting thresholds $\widetilde{m}_{j B}^{V}$ and $\widetilde{z}_{j B}$ reduce to the values obtained with absentee ownership, i.e., to zero and $\widetilde{z}_{j B}-t_{j B}$, respectively (see (16) and (17)). Briefly, if taxes are too large, even native ownership cannot prevent approval from falling as mobility rises. Conversely, if taxes are sufficiently light, native ownership permits approval to rise 
with mobility, in a monotonic fashion (Proposition 6, Part (ii)).

Housing property rights matter for how changes in country $j$ 's mobility affect project approval in $j$ 's border region $j B$. By contrast, greater mobility in $j$ raises support for the integration project in $i B$ regardless of $i$ 's ownership regime. For instance, greater mobility in Poor reinforces the supply of cross-border services, causing the service price to drop. This unambiguously benefits Rich shoppers, making more of them inclined to welcome the project (Proposition 6, Part (iii)). Since Rich Border becomes more attractive, Rich Border rent rises subsequently. With native ownership, Rich Border natives, who move to Rich Interior and lease their houses in Border, gain from a larger rent differential. Thus support is reinforced even more under this ownership regime.

\subsection{Complementarity of Regional and (Inter-)National Poli- cies}

Initial transaction costs $\bar{\theta}$ as well as the leeway $\bar{\theta}-\underline{\theta}$ are determined at the national and international levels. These levels depend on the border control regulations and other issues not under the control of the local authorities, as discussed above. In this section we analyse how these exogenous policy parameters affect the regional political support for the integration project. More precisely, while we assume that project costs (and thus the tax burden) do not change, transaction costs (with or without the project's implementation) vary due to exogenous policy changes at the national or international levels. Our findings are summarised in

\section{Proposition 7: Voting and (Inter-)National Policies}

(i) Irrespective of the ownership regime, the project supporters' shares $V_{P B}$ and $V_{R B}$ are decreasing in transaction costs $\underline{\theta}$.

(ii) With absentee ownership, project supporters' shares $V_{P B}$ and $V_{R B}$ increase if the pre-project transaction costs $\bar{\theta}$ fall.

The Proposition's first part is not surprising. It simply says that the more effectively the project lowers transaction costs, the broader its political support will be. This is as we should expect it to be. For example, the central governments of Poor and Rich could decide to ease border controls for public transport, thus reducing transaction $\operatorname{costs} \underline{\theta}$ if the local authorities build a tram connection across the border. Such a measure at the international level would obviously strengthen approval for public transport across the border.

The Proposition's second part is far less obvious. If, in the case of absentee ownership, central governments cut those transaction costs that apply if the project is not carried out, support for the integration project nonetheless increases. To understand this conclusion, let us consider the group of individuals who become cross-border sellers once the project is carried out, but nevertheless oppose cross- 
border integration politically. For these households, the income gain net of cultural costs cannot compensate for the attendant increase in taxes and rents. However, the lower the option $\bar{\theta}$, the higher the rents, even if the electorate rejects the project. In other words, option $\bar{\theta}$ becomes less attractive and, consequently, the integration project becomes relatively more attractive. Therefore, more native cross-border sellers support integration and the share of votes for the project increases. Note, however, that this argument is only valid if cross-border sellers native to Poor Border suffer from higher rents, which is only the case with absentee ownership. With native ownership, by contrast, Poor Border natives are not concerned with rising rents, and the share of votes for the project does not increase in response to declining pre-project transaction costs $\bar{\theta}$. (A similar line of reasoning can be applied for Rich Border.)

Proposition 7 further highlights the fact that the welfare and political-economic implications of changes in the environment can be diametrically opposite. While a decline in the initial transaction costs $\bar{\theta}$ reduces the project's aggregate benefits reflected in $A W T P$ (Proposition 4, Part (ii)), in the case of absentee ownership this decline also strengthens political support for the project. Projects that generate lower benefits might gain more votes than those that result in higher benefits.

While a favourable environment in terms of low $\underline{\theta}$ and $\bar{\theta}$ strengthens local support for the integration project, a grant $s_{j}$ from country $j$ 's central government (or any international institution) to partly cover project costs $e_{j}$ cannot necessarily do the job. This conclusion holds even if Border natives do not contribute at all to funding this grant, as we assume.

\section{Proposition 8: Voting and Federal Grants}

With absentee ownership, a grant $s_{j}$ from $j$ 's central government that reduces local taxes to $e_{j}-s_{j}$ does not affect the share of the project's supporters $V_{j B}$. With native ownership, in contrast, the share of project supporters $V_{j B}$ is increasing in such a central grant $s_{j}$.

These results follow directly from the tax and subsidy incidence in the economy (as formally proved in the appendix). A central grant curbs the local tax burden caused by the project, but the induced cut in taxes is wholly capitalised in rents. Thus, with absentee ownership, the grant does not relieve Border's natives, but only benefits the landlords outside Border. Only if Border's natives own their houses, i.e., only in the case of native ownership, do they gain from this subsidy and overall support for the project rises.

Of course, the clarity of a grant's incidence hinges on the assumption that land supply is fixed. Otherwise Border natives would benefit at least partly from a central grant, and this central grant would enhance support for the integration project even with absentee ownership. The crucial point is, however, that, even in this extreme case with fixed land supply, central governments can influence local 
voting, by manipulating the upper and lower bound of locally achievable transaction costs, $\underline{\theta}$ and $\bar{\theta}$. Obviously, the incidence of such indirect policies differs from that of grants, and it is worthwhile paying attention to these differences.

\section{Discussion}

Despite the potential welfare gains from cross-border shopping, transaction costs remain high in many border regions, even when they could be lowered. We have shown that this outcome can be intended, and backed, by a majority. We have pointed to four major political obstacles to cross-border regional integration. First, cultural costs of a majority of people might be too high. As high-cost types refrain from cross-border interaction, they cannot benefit from any integration project. High-cost types are exposed only to the project's drawbacks. Not only do they oppose the integration project, they also might even constitute a majority even when aggregate willingness-to-pay for the project is positive.

Second, intra-country mobility might also be too high. At first this statement might surprise. After all, at the heart of the problem is that the 'wrong' types of individuals are native to border regions. So one might hope that greater mobility provides a remedy for the political bias against cross-border integration. In mobile societies, however, any improvement in the border region attracts individuals to this region. This inflow of additional beneficiaries of cross-border trade comes at the expense of the initial residents. In Poor, for example, this inflow depresses wages in the cross-border services industry and drives up rents, thus diminishing political support for the integration project (at least with absentee ownership).

So realising welfare gains can be a difficult task politically for local jurisdictions embedded in a federal structure with open boundaries. This point seems to be neglected, given that the economic literature puts much stress on inefficiencies that arise from inter-jurisdictional competition for production factors. Our line of reasoning implies that any policy aimed at promoting intra-country mobility can be detrimental to cross-border integration. But this argument has to be treated with some caution. With greater mobility, more individuals with high cultural ability might be attracted to the border regions even if integration projects are initially rejected. Since such an inflow would change political majorities in the very long run, it could ultimately pave the way for the political success of integration projects.

Third, the ownership regime can hamper political support for the integration project. Integration raises rents in Border, but, with absentee ownership, the resultant income does not stay with Border natives. By contrast, with native ownership, local voters can additionally benefit from rent increases, strengthening the support for the project. Consequently, any policy that promotes people to invest in their own homes, thus creating local ownership, strengthens support for 'sensible' local public investments. 
Note that the assumption that land supply is fixed in the Borders exaggerates the relevance of the ownership structure, since it obviously overstates rent gains. Allowing for land development in the border regions softens the effects associated with rents, but does not eliminate the fundamental importance of ownership. Also, for our analysis, only the ownership of land in Border matters, since rent gains accrue only there. The two regimes considered are thus sufficient to capture the extreme cases that can arise. Furthermore, we expect that, if a region becomes more attractive, rents rise in this region rather than fall in other regions. This notion is reflected in our model by tying Interior rents to $d_{j}$.

Fourth, central governments might give regional authorities too little leeway, limiting the success of regional integration projects. Again, this undermines political support for projects. It also shows that favourable (inter-)national policies leading to low transaction cost levels $\underline{\theta}$ and $\bar{\theta}$ can trigger accompanying measures at the regional level and thus generate 'multiplier' effects. As we have already discussed above, such a strategy might be more successful than providing grants to local governments.

Finally, let us emphasise that, while analysing specific features of integration across border regions in this paper, we also cover many problems of economic integration in general. For instance, many measures that broaden support for integration projects also make the drawbacks more pronounced. Lowering the transaction cost level $\underline{\theta}$ increases the number of Border natives who benefit from the project. But the additional trade gains also reinforce the rise in rents in Border. Thus greater support and larger aggregate willingness-to-pay for a project go along with greater losses for those on the losing side. We think this conflict occurs in many cases of economic integration. This can explain why integration projects that promise high welfare gains face particularly fierce opposition. In this sense, cross-border integration is globalisation in a nutshell.

\section{Concluding Remarks}

We have given a political-economic explanation for why regional integration across borders might fail to appeal to the electorate even if it is welfare enhancing. On the one hand, the analysis stresses the specific circumstances in border regions and the relationships of these regions to central governments and their hinterlands. On the other hand, it reveals the conflicts of economic integration in general. Our conclusions might thus be relevant to a range of other issues related to economic integration in a broad sense. Since we focus on the role of cultural ability and intercultural contacts in services, our approach could also be applied to analysing tourism. Projects to develop tourist spots yield relatively well-paid jobs for those workers who like to interact with foreigners, but they also drive up rents. Individuals with low cultural costs are expected to flock into tourist areas and crowd out those 
with high costs, etc. The similarities between promoting cross-border shopping and tourism are striking. We leave the details to a follow-up paper.

Also, we intend to further explore the relationships between border regions. For instance, we have not said anything about how the project cost shares come about. They must result from negotiations between the local authorities on both sides of borders and will be shaped by the institutional arrangement in which the regions operate. This gives plenty of opportunities to act strategically at the local and federal levels. Moreover, we plan to investigate the role of the services suppliers on the rich side who have good reasons to lobby against integration. We leave these issues also to a future paper. 


\section{References}

Alesina, A., R. Baqir, and C. Hoxby (2004) Political Jurisdictions in Heterogeneous Communities, Journal of Political Economy 112: 248-396.

Balassa, B. (1964) The Purchasing-Power Parity Doctrine: A Reappraisal, Journal of Political Economy 72: 584-596.

Calabrese et al. (2005) Local Public Good Provision: Voting, Peer Effects and Mobility, NBER Working Paper 11720.

Epple, D., R. Filimon and T. Romer (1984) Equilibrium among Local Jurisdictions: Toward and Integrated Treatment of Voting and Residential Choice, Journal of Public Economics 24: 281-308.

Epple, D., R. Filimon and T. Romer (1993) Existence of Voting and Housing equilibrium in a System of Communities with Property Taxes, Regional Science and Urban Economics 23: 585-610.

Epple, D., Th. Romer and H. Sieg (2001) Interjurisdictional Sorting and Majority Rule: An Empirical Analysis, Econometrica 69: 1437-1465.

Frank, R. (1987) Choosing the Right Pond: Human Behavior and the Quest for Status, Oxford: Oxford University Press.

Grunwald, J. (1985) The Assembly Industry in Mexico, in: Grunwald, J. and K. Flamm (eds), Global Factory: Foreign Assembly in International Trade, Brookings.

Hansen, N. and A. Kessler (2001) The Political Geography of Tax H(e)avens and Tax Hells, American Economic Review 91: 1103-1115.

Hanson, G. (1996) Economic Integration, Intraindustry Trade, and Frontier Regions, European Economic Review 40: 941-949.

Hanson, G. (2001) U.S. Mexico Integration and Regional Economies: Evidence from Border-City Pairs, Journal of Urban Economics 50: 259-287.

Haufler, A. (2001) Taxation in a Global Economy, Cambridge: Cambridge University Press.

Kanbur, R. and M. Keen (1993) Jeux sans Frontières: Tax Competition and Tax Coordination When Countries Differ in Size, American Economic Review 83: 877-892.

Kessler, A. and Ch. Lülfesmann (2005) Tiebout and Redistribution in a Model of Residential and Political Choice, Journal of Public Economics 89: 501-528.

Lazear, E., U. Malmendier and R. Weber (2006) Sorting in Experiments with Application to Social Preferences, NBER Working Paper 12041. 
Mansoorian, A. and G. Myers (1993) Attachment to Home and Efficient Purchasese of Population in a Fiscal Externality Economy, Journal of Public Economics 52: $117-32$.

Lucas, V. (2004) Cross-Border Shopping in a Federal Economy, Regional Science and Urban Economics 34: 365-385.

Nielsen, S. (2001) A Simple Model of Commodity Taxation and Cross-Border Shopping, Scandinavian Journal of Economics 103: 599-623.

Nielsen, S. (2002) Cross-Border-Shopping from Small to Large Countries, Economics Letters 77: 309-313.

Samuelson, P. (1964) Theoretical Notes on Trade Problems, Review of Economics and Statistics 23: 145-154.

Westhoff, F. (1979) Policy Inferences from Community Choice Models: A Caution, Journal of Urban Economics 6: 535-549.

Wildasin, D. (1986) Urban Public Finance, Chur: Harwood. 


\section{Appendix}

Lemma 1: $\widetilde{z}_{P B}-\widetilde{m}_{P B}$ is increasing in $p_{C}$, and $\widetilde{z}_{R B}-\widetilde{m}_{R B}$ is decreasing in $p_{C}+\theta$.

Proof of Lemma 1: We only show the Lemma's first part. The proof of its second part is similar. Using $(7),(8)$ and (12) we may rewrite $\widetilde{z}_{P B}-\widetilde{m}_{P B}$ as:

$$
\widetilde{z}_{P B}-\widetilde{m}_{P B}=\widetilde{z}_{P B}\left(2 \bar{z}_{P}-\widetilde{z}_{P B}\right) \frac{1}{2 \bar{z}_{P}}
$$

Pick two different levels of $\widetilde{z}_{P B}$, i.e., $\widetilde{z}_{P B}^{\prime}<\widetilde{z}_{P B}^{\prime \prime}$. Then

$$
\begin{aligned}
0 & <\left(\widetilde{z}_{P B}^{\prime \prime}-\widetilde{z}_{P B}^{\prime}\right)\left(2 \bar{z}_{P}-\widetilde{z}_{P B}^{\prime}-\widetilde{z}_{P B}^{\prime \prime}\right) \\
\Leftrightarrow \quad \widetilde{z}_{P B}\left(\widetilde{z}_{P B}^{\prime \prime}-\widetilde{z}_{P B}^{\prime}\right) & <\left(\widetilde{z}_{P B}^{\prime \prime}-\widetilde{z}_{P B}\right)\left(2 \bar{z}_{P}-\widetilde{z}_{P B}^{\prime \prime}\right) \\
\Leftrightarrow \quad \widetilde{z}_{P B}^{\prime}\left(2 \bar{z}_{P}-\widetilde{z}_{P B}^{\prime}\right) / 2 \bar{z}_{P} & <\widetilde{z}_{P B}^{\prime \prime}\left(2 \bar{z}_{P}-\widetilde{z}_{P B}^{\prime \prime}\right) / 2 \bar{z}_{P}
\end{aligned}
$$

The third inequality follows from adding $\widetilde{z}_{P B}^{\prime}\left(2 \bar{z}_{P}-\widetilde{z}_{P B}^{\prime \prime}\right)$ to both sides of the second, and dividing through by $2 \bar{z}_{P}$. We conclude that $\widetilde{z}_{P B}-\widetilde{m}_{P B}$ is increasing (i.e., strictly increasing) in $\widetilde{z}_{P B}$. Since $\widetilde{z}_{P B}$ is increasing in $p_{C}$ (see (4) and (7), $\widetilde{z}_{P B}-\widetilde{m}_{P B}$ is increasing in $p_{C}$.

\section{Proof of Proposition 1: ShoMig Equilibrium}

Part (i): By inspection of Figure 1,

$$
\begin{aligned}
Y_{P}\left(p_{C}, \bar{m}_{P}\right) & =\left[\bar{m}_{P} \widetilde{z}_{P B}+\left(\bar{z}_{P}-\widetilde{z}_{P B}\right) \widetilde{m}_{P B}\right] \frac{b N_{P}}{\bar{z}_{P} \bar{m}_{P}} \\
Y_{R}\left(p_{C}, \theta, \bar{m}_{R}\right) & =\left[\bar{m}_{R} \widetilde{z}_{R B}+\left(\bar{z}_{R}-\widetilde{z}_{R B}\right) \widetilde{m}_{R B}\right] \frac{N_{R}}{\bar{z}_{R} \bar{m}_{R}}
\end{aligned}
$$

Define excess demand as

$$
E\left(p_{C}, \theta, \bar{m}_{P}, \bar{m}_{R}\right) \equiv Y_{R}\left(p_{C}, \theta, \bar{m}_{R}\right)-Y_{P}\left(p_{C}, \bar{m}_{P}\right)
$$

Since $\widetilde{z}_{j B}$ is continuous in $p_{C}$ (see $(4)$ and $(7)$ ), so is $\widetilde{m}_{j B}$ (see (12)). Hence $Y_{P}$ and $Y_{R}$ are continuous in $p_{C}$, too (see (19) and (20)). Since the sum of two continuous functions is continuous, excess demand $E$ is continuous in $p_{C}$. Finally, $Y_{P}\left(p_{P}, \bar{m}_{P}\right)=0$, and therefore $E\left(p_{P}, \theta, \bar{m}_{P}, \bar{m}_{R}\right)=Y_{R}\left(p_{P}, \theta, \bar{m}_{R}\right)>0$; whereas $Y_{R}\left(p_{R}-\theta, \theta, \bar{m}_{R}\right)=0$, and so $E\left(p_{R}-\theta, \theta, \bar{m}_{P}, \bar{m}_{R}\right)=-Y_{P}\left(p_{R}-\theta, \bar{m}_{P}\right)<0$. Thus, by the intermediate value theorem, there exists $p_{C}^{*} \in\left(p_{P}, p_{R}-\theta\right)$ for which $E\left(p_{C}^{*}, \theta, \bar{m}_{P}, \bar{m}_{R}\right)=0$. Either $Y_{P}\left(p_{C}^{*}, \bar{m}_{P}\right)$ or $Y_{R}\left(p_{C}^{*}, \theta, \bar{m}_{R}\right)$ give the equilibrium quantity $Y^{*}$.

Part (ii): Since $\widetilde{z}_{P B}$ and $\widetilde{m}_{P B}$ are increasing in $p_{C}$ (see $(7)$ and (12)), point $\left(\widetilde{m}_{P B}, \widetilde{z}_{P B}\right)$ also is increasing in $p_{C}$, in the natural order of $\mathcal{R}^{2}$. Clearly, $Y_{P}$ is then increasing in $p_{C}$. Similarly, since $\widetilde{z}_{R B}$ and $\widetilde{m}_{R B}$ are decreasing (i.e., strictly decreasing) in $\left(p_{C}+\theta\right)$ (see $(7)$ and $(12)$ ), point $\left(\widetilde{m}_{R B}, \widetilde{z}_{R B}\right)$ is decreasing in $p_{C}$. Clearly, $Y_{R}$ is then decreasing in $\left(p_{C}+\theta\right)$, and hence in $p_{C}$ and $\theta$. 
Since $-Y_{P}$ is decreasing in $p_{C}$, excess demand $E$ as the sum of two decreasing functions is also decreasing in $p_{C}$. Then it is straightforward to show that equilibrium is unique. Assume there are two different equilibrium prices, $p_{C}^{*}$ and $p_{C}^{* *}$. Suppose $p_{C}^{*}<p_{C}^{* *}$. Then $E\left(p_{C}^{*}\right)=E\left(p_{C}^{* *}\right)$. But then $E$ is not decreasing in $p_{C}$. This is a contradiction.

Part (iii): Note first the following three properties of the excess demand function. Since $E$ is decreasing in $p_{C}+\theta$ (Proof of Part (ii)), $E$ is decreasing in $\theta$ for given $p_{C}$ and $\theta \in\left[0, p_{R}-p_{P}\right]$. Next, since $Y_{R}$ is decreasing in $\bar{m}_{R}$ for given $p_{C}$ and for $\bar{m}_{R}$ positive and finite, so is $E$ (see (20)). Finally, since $-Y_{P}$ is increasing in $\bar{m}_{P}$ for given $p_{C}$ and for $\bar{m}_{P}$ positive and finite, again so is $E$ (see (19)).

Changes in $\theta, \bar{m}_{R}$ and $\bar{m}_{P}$ shift excess demand. But excess demand remains continuous on $\left[p_{P}, p_{R}-\theta\right]$, and decreasing in $p_{C}$. Moreover, changes in $\theta$ affect excess demand's domain. But excess demand remains continuous on its domain, and decreasing in $p_{C}$. Equilibrium continues to exist, and, in particular, to be unique. Thus equilibrium values for $p_{C}, Y, r_{j B}, M_{j B}, M_{j I}$ and $C_{j B}$ are functions of parameters $\theta, \bar{m}_{P}$ and $\bar{m}_{R}$.

\section{Proof of Proposition 2: ShoMig Equilibrium and the Integration Project}

Part (i): (a) Assume that the equilibrium price $p_{C}$ is not decreasing in $\theta$. That is, assume that there exist two different transaction costs $\theta^{\prime}<\theta^{\prime \prime}$ with corresponding equilibrium prices $p_{C}^{\prime} \leq p_{C}^{\prime \prime}$. Note first that $0=E\left(p_{C}^{\prime \prime}, \theta^{\prime \prime}\right)$, by definition. Next, $E\left(p_{C}^{\prime \prime}, \theta^{\prime \prime}\right)<E\left(p_{C}^{\prime \prime}, \theta^{\prime}\right)$, given that $E$ is decreasing in $\theta$ (Proposition 1, Proof of Part (iii)). And, $E\left(p_{C}^{\prime \prime}, \theta^{\prime}\right) \leq E\left(p_{C}^{\prime}, \theta^{\prime}\right)$ given that $E$ is decreasing in $p_{C}$ (Proposition 1, Proof of Part (ii)). Joining (in)equalities yields $0<E\left(p_{C}^{\prime}, \theta^{\prime}\right)$. But then $p_{C}^{\prime}$ is not the equilibrium price for $\theta^{\prime}$. This is a contradiction.

(b) Equilibrium supply $Y_{P}$ is increasing in $p_{C}$ (Proposition 1, Proof of Part (ii)). Since $p_{C}$ is decreasing in $\theta$ (see (a)), $Y_{P}$ also is decreasing in $\theta$. Since $Y_{P}$ is decreasing in $\theta$, equilibrium demand $Y_{R}$ and cross border sales $Y$ are decreasing in $\theta$.

(c) Equilibrium demand $Y_{R}$ is decreasing in $\left(p_{C}+\theta\right)$ (Proposition 1, Proof of Part (ii)). Since the inverse of a decreasing function is decreasing, $\left(p_{C}+\theta\right)$ is decreasing in $Y_{R}$. Since $Y_{R}$ is decreasing in $\theta$ (see (b)), $\left(p_{C}+\theta\right)$ is increasing in $\theta$.

(d) Wage $w_{C}$ is increasing in $p_{C}$, by inspection of (4). Since $p_{C}$ is decreasing in $\theta$ (see (a)), $w_{C}$ also is decreasing in $\theta$.

(e) Poor Border rent $r_{P B}$ is increasing in $p_{C}$, by inspection of (12) jointly with (5), (7) and (8). Since $p_{C}$ is decreasing in $\theta$ (see (a)), $r_{P B}$ also is decreasing in $\theta$.

(f) Rich Border rent $r_{R B}$ is decreasing in $\left(p_{C}+\theta\right)$, by inspection of (12) joint with (5), (7) and (8). Since $\left(p_{C}+\theta\right)$ is increasing in $\theta$ (see (c)), $r_{R B}$ is decreasing in $\theta$.

Part (ii) (a) Consider first the intersection of the $\widehat{z}_{P B}$-line with the $z$-axis (see Figure 1 for illustration). Since $\widetilde{z}_{P B}-\widetilde{m}_{P B}$ is increasing in $p_{C}$ (see Lemma 1), and since 
$p_{C}$ is decreasing in $\theta$ (Proof of Part (i), (a)), intersection $\widetilde{z}_{P B}-\widetilde{m}_{P B}$ is decreasing in $\theta$. Consider next the intersection of the $\widetilde{z}_{P B}$-line with the $z$-axis. Since $\widetilde{z}_{P B}$ is increasing in $p_{C}$ (see (7)), and since $p_{C}$ is decreasing in $\theta$ (see Proof of Part (i), (a)), $\widetilde{z}_{P B}$ is decreasing in $\theta$. Since both intersections are decreasing in $\theta$, and since $C_{P B}$ is increasing in this pair of intersections (as is apparent from Figure 1), we conclude that $C_{P B}$ is decreasing in $\theta$.

(b) Note that $M_{P I}=0.5\left(\widetilde{z}_{P B}-\widetilde{m}_{P B}\right)^{2}$. Since $\left(\widetilde{z}_{P B}-\widetilde{m}_{P B}\right)$ is decreasing in $\theta$ (Proof of (a)), $M_{P I}$ also is decreasing in $\theta$.

(c) Since $\widetilde{z}_{R B}$ is decreasing in $p_{C}+\theta$ (see (5) and (7)), and since $p_{C}+\theta$ is increasing in $\theta$ (Proof of Part (i), (c)), $\widetilde{z}_{R B}$ is decreasing in $\theta$. Next, since $\widetilde{z}_{R B}-\widetilde{m}_{R B}$ is decreasing in $p_{C}+\theta$ (see Lemma 1), and since $p_{C}+\theta$ is increasing in $\theta$ (again, Proof of Part (i), (c)), $\widetilde{z}_{R B}-\widetilde{m}_{R B}$ is decreasing in $\theta$. Along lines similar to (a) we conclude that $C_{R B}$ is decreasing in $\theta$.

(d) Note that $M_{R I}$ equals $0.5\left(\widetilde{z}_{R B}-\widetilde{m}_{R B}\right)^{2}$. Since $\widetilde{z}_{R B}-\widetilde{m}_{R B}$ is decreasing in $\theta$ (Proof of (c)), $M_{R I}$ also is decreasing in $\theta$.

Part (iii) By virtue of (12), replace $\widetilde{m}_{j B}$ on the r.h.s. of (19) and (20) by $\left[\widetilde{z}_{j B}\right]^{2} / 2 \bar{z}_{j}$. Both service supply and service demand thus are functions of $\widetilde{z}_{P B}$ and $\widetilde{z}_{R B}$. Since $\widetilde{z}_{P B}$ and $\widetilde{z}_{R B}$ themselves are functions of $p_{C}$ (see $(7)$ ), service supply and demand depend on $p_{C}$ and exogenous parameters $\bar{m}_{j}, \bar{z}_{j}, N_{j}, \theta$ and $b$; but service supply and service demand do not depend on taxes $t_{j B}$. This reveals that $p_{C}$ must be constant in taxes $t_{P B}$ and $t_{R B}$. Hence so are cross-border sales $Y$, and so is cross-border sellers' wage $w_{C}$.

Moreover, given that $p_{C}$ is constant in taxes, so are $\widetilde{z}_{P B}$ and $\widetilde{z}_{R B}$ (see $(7)$ ) as well as, again by virtue of (12), $\widetilde{m}_{P B}$ and $\widetilde{m}_{R B}$. Since $\widetilde{m}_{P B}$ and $\widetilde{m}_{R B}$ are invariant under changes in taxes, any change in $\operatorname{tax} t_{j B}$ must entirely capitalize into rent differential $\Delta r_{j B}$ (see (8)) and Border rent $r_{j B}$. In particular, rent $r_{j B}$ is decreasing in $t_{j B}$.

\section{Proof of Proposition 3: ShoMig Equilibrium and Interregional Mobility}

We focus on comparative statics with respect to $\bar{m}_{P}$. The proof of comparative statics properties with respect to $\bar{m}_{R}$ is similar.

Part (i): (a) Assume that the equilibrium price $p_{C}$ is not increasing in $\bar{m}_{P}$. That is, assume that there exist two different mobility parameters $\bar{m}_{P}^{\prime}<\bar{m}_{P}^{\prime \prime}$ with corresponding equilibrium prices $p_{C}^{\prime} \geq p_{C}^{\prime \prime}$. Note first that $0=E\left(p_{C}^{\prime \prime}, \bar{m}_{P}^{\prime \prime}\right)$ by definition. Next, $E\left(p_{C}^{\prime \prime}, \bar{m}_{P}^{\prime \prime}\right)>E\left(p_{C}^{\prime \prime}, \bar{m}_{P}^{\prime}\right)$, given that $E$ is increasing in $\bar{m}_{P}$ (Proposition 1, Proof of Part (iii)). And, $E\left(p_{C}^{\prime \prime}, \bar{m}_{P}^{\prime}\right) \geq E\left(p_{C}^{\prime}, \bar{m}_{P}^{\prime}\right)$, given that $E$ is decreasing in $p_{C}$ (Proposition 1, Proof of Part (ii)). Joining (in)equalities yields $0>E\left(p_{C}^{\prime}, \bar{m}_{P}^{\prime}\right)$. Hence $p_{C}^{\prime}$ is not the equilibrium price given $\bar{m}_{P}^{\prime}$. This is a contradiction.

(b) Wage $w_{C}$ is increasing in $p_{C}$, by inspection of (4). Since $p_{C}$ is increasing in $\bar{m}_{P}$ (see (a)), $w_{C}$ is increasing in $\bar{m}_{P}$. 
(c) Equilibrium demand $Y_{R}$ is decreasing in $p_{C}$ (Proposition 1, Proof of Part (ii)). Since $p_{C}$ is increasing in $\bar{m}_{P}$ (see (a)), $Y_{R}$ is decreasing in $\bar{m}_{P}$. But then equilibrium supply $Y_{P}$, and hence cross border equilibrium sales $Y$, are also decreasing in $\bar{m}_{P}$.

(d) Poor Border rent $r_{P B}$ is increasing in $p_{C}$, by inspection of (12) joint with (5), (7) and (8). Since $p_{C}$ is increasing in $\bar{m}_{P}$ (see (a)), $r_{P B}$ is also increasing in $\bar{m}_{P}$.

(e) Rich Border rent $r_{R B}$ is decreasing in $p_{C}$, by inspection of (12) jointly with (5), (7) and (8). Since $p_{C}$ is increasing in $\bar{m}_{P}$ (see (a)), $r_{R B}$ is decreasing in $\bar{m}_{P}$.

Part (ii): (a) Consider the intersection of the $\widetilde{z}_{P B}$-line with the $z$-axis first, i.e., $\widetilde{z}_{P B}$. Since $\widetilde{z}_{P B}$ is increasing in $p_{C}$ (see $(7)$ ), and since $p_{C}$ is increasing in $\bar{m}_{P}$ (Part (i), (a)), $\widetilde{z}_{P B}$ is increasing in $\bar{m}_{P}$. Consider next the intersection of the $\widehat{z}_{P B}$-line with the $z$-axis, i.e., $\widetilde{z}_{P B}-\widetilde{m}_{P B}$. Suppose $\bar{m}_{P}^{\prime}<\bar{m}_{P}^{\prime \prime}$. We distinguish between two cases. In the first case $\widetilde{z}_{P B}^{\prime \prime}-\widetilde{m}_{P B}^{\prime \prime} \geq \widetilde{z}_{P B}^{\prime}$. Then $C_{P B}^{\prime \prime}>C_{P B}^{\prime}$ is obvious. In the second case, where $\widetilde{z}_{P B}^{\prime \prime}-\widetilde{m}_{P B}^{\prime \prime}<\widetilde{z}_{P B}^{\prime}$, this inequality is somewhat less obvious. However,

$$
\begin{aligned}
C_{P B}^{\prime} & =\left[\widetilde{z}_{P B}^{\prime} \bar{m}_{P}^{\prime}-0.5\left(\widetilde{m}_{P B}^{\prime}\right)^{2}\right] \frac{N_{P}}{\bar{m}_{P}^{\prime} \bar{z}_{P}} \\
& <\left[\widetilde{z}_{P B}^{\prime} \bar{m}_{P}^{\prime \prime}-0.5\left(\widetilde{m}_{P B}^{\prime}\right)^{2}\right] \frac{N_{P}}{\bar{m}_{P}^{\prime \prime} \bar{z}_{P}} \\
& <\left[\widetilde{z}_{P B}^{\prime} \bar{m}_{P}^{\prime \prime}-0.5\left(\widetilde{z}_{P B}^{\prime}-\left(\widetilde{z}_{P B}^{\prime \prime}-\widetilde{m}_{P B}^{\prime \prime}\right)\right)^{2}\right] \frac{N_{P}}{\bar{m}_{P}^{\prime \prime} \bar{z}_{P}} \\
& <\left[\widetilde{z}_{P B}^{\prime \prime} \bar{m}_{P}^{\prime \prime}-0.5\left(\widetilde{z}_{P B}^{\prime \prime}-\left(\widetilde{z}_{P B}^{\prime \prime}-\widetilde{m}_{P B}^{\prime \prime}\right)\right)^{2}\right] \frac{N_{P}}{\bar{m}_{P}^{\prime \prime} \bar{z}_{P}} \\
& =\left[\widetilde{z}_{P B}^{\prime \prime} \bar{m}_{P}^{\prime \prime}-0.5\left(\widetilde{m}_{P B}^{\prime \prime}\right)^{2}\right] \frac{N_{P}}{\bar{m}_{P}^{\prime \prime} \bar{z}_{P}}=C_{P B}^{\prime \prime}
\end{aligned}
$$

The second inequality follows from the first by the fact that $\widetilde{z}_{P B}^{\prime}-\left(\widetilde{z}_{P B}^{\prime \prime}-\widetilde{m}_{P B}^{\prime \prime}\right)<$ $\widetilde{m}_{P B}^{\prime}$, as apparent from Figure 4 . The third inequality follows from the second by comparison of the corresponding areas in Figure 4 . We conclude that $C_{P B}$ is increasing in $\bar{m}_{P}$.

(b) Since cross border sales $Y_{P}$ and hence the total number of cross-border sellers $Y_{P} / b$ are decreasing in $\bar{m}_{P}$ (Part (i),(c)), and since $C_{P B}$ is increasing in $\bar{m}_{P}$ (see (a)), $M_{P I}=Y_{P} / b-C_{P B}$ as the sum of two decreasing functions, $Y_{P} / b$ and $-C_{P B}$, must be decreasing in $\bar{m}_{P}$.

Part (iii): (a) Recall that $\widetilde{z}_{R B}$ and $\widetilde{z}_{R B}-\widetilde{m}_{R B}$ are both decreasing in $p_{C}$ (see (7) and Lemma 1). Hence $C_{R B}$ is decreasing in $p_{C}$. Since $p_{C}$ is increasing in $\bar{m}_{P}$ (Part (i), (a)), $C_{R B}$ is decreasing in $\bar{m}_{P}$.

(b) Note that $M_{R I}=0.5\left(\widetilde{z}_{R B}-\widetilde{m}_{R B}\right)^{2}$. Since $M_{R I}$ is increasing in $\widetilde{z}_{R B}-\widetilde{m}_{R B}$, since $\widetilde{z}_{R B}-\widetilde{m}_{R B}$ is decreasing in $p_{C}$ (see Lemma 1 ), and since $p_{C}$ is increasing in $\bar{m}_{P}$ (Part (i), (a)), $M_{R I}$ is decreasing in $\bar{m}_{P}$. 


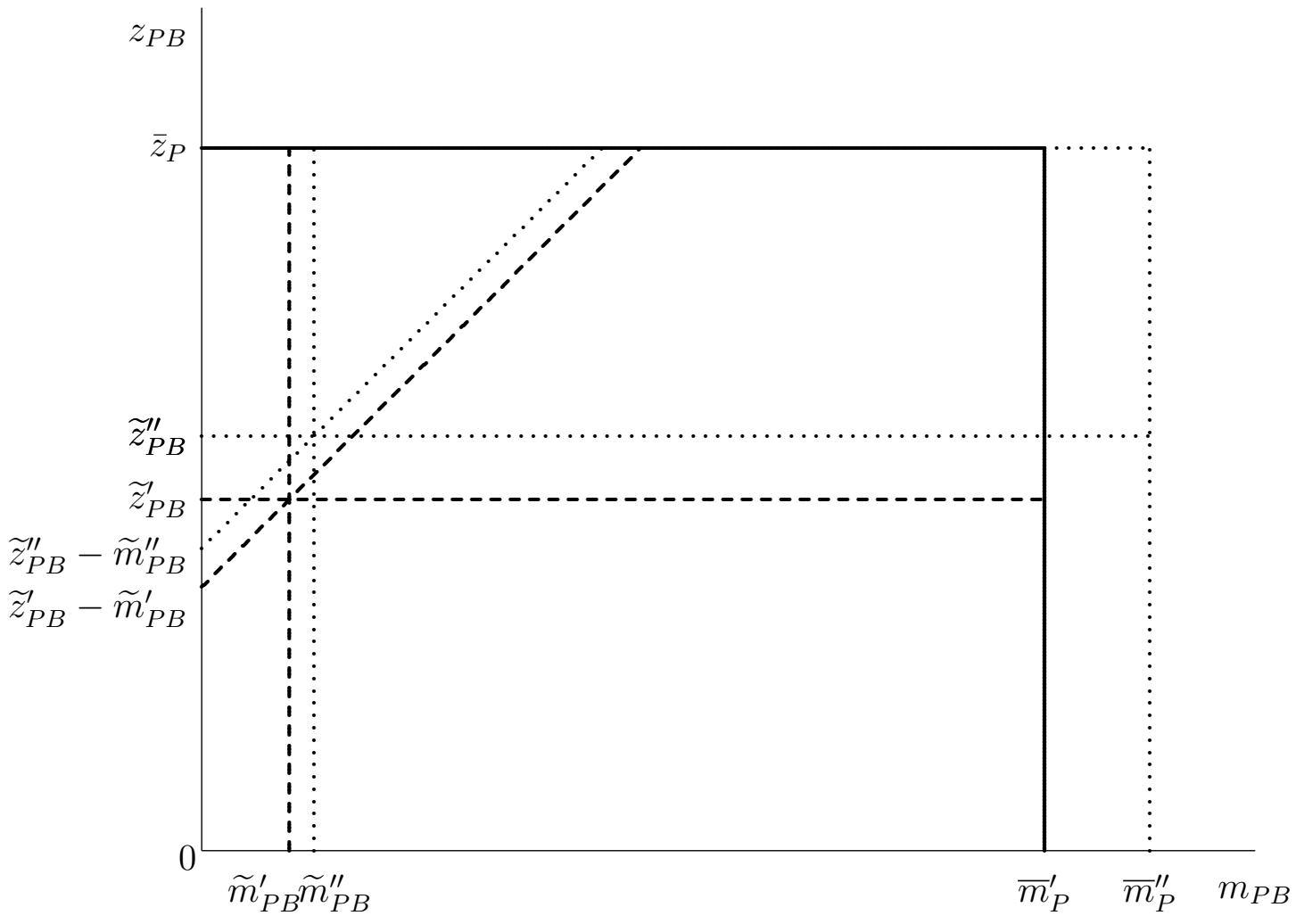

Figure 4: An Increase in Mobility Cost in Poor

\section{Proof of Proposition 4: Integration and Welfare}

Part (i): Since individuals' redistributive gains owed to changes in Border rents (given by Table 1's last column) cancel out, computation of $A W T P$ reduces to integration over individuals' real gains (given by Table 1's third column).

Now, taxes $t_{P B}$ and $t_{R B}$ are constant across individuals. This permits us to write $A W T P$ as the sum of aggregate tax payments $-N_{P} t_{P B}+N_{R} t_{R B}$ and a second term capturing those aggregate real gains that arose if project costs were zero:

$$
A W T P\left(\bar{\theta}, \underline{\theta}, t_{P B}, t_{R B}\right)=-\left(N_{P} t_{P B}+N_{R} t_{R B}\right)+A W T P(\bar{\theta}, \underline{\theta}, 0,0)
$$

(a) Since taxes $t_{P B}$ and $t_{R B}$ do not alter the sets into which indifference loci partition the support of $F_{j}$ (Proof of Proposition 2, Part (iii)), the second term on the r.h.s. of (22) is constant in $t_{P B}$ and $t_{R B}$. Taxes only have that direct effect captured by the first term on the r.h.s. of (22). Since that term is obviously decreasing in $t_{P B}$ and $t_{R B}$, then so is $A W T P\left(\bar{\theta}, \underline{\theta}, t_{P B}, t_{R B}\right)$.

(b) Next we show that $A W T P(\bar{\theta}, \underline{\theta}, 0,0)>0$. - Rather than explicitly computing $A W T P(\bar{\theta}, \underline{\theta}, 0,0)$, we extract its sign as follows. Any Poor Border native turned cross-border seller reveals $z_{P B}<\widetilde{z}_{P B}$. For this household, $w_{C}-w_{P}-z_{P B}>0$, given (7). Any Poor Border native turned emigrant reveals $m_{P B}<\widetilde{m}_{P B}$. Hence $\Delta r_{P}>m_{P B}$, given (8). That is, any emigrant's real loss is bounded from above, by 
$\Delta r_{P}$. Finally, any Poor Interior native migrating into Poor Border reveals $z_{P I}<\widetilde{z}_{P I}$. Hence $w_{C}-w_{P}-z_{P I}-m_{P I}>\Delta r_{P}$, given (11). That is, any immigrant's real gain is bounded from below, by $\Delta r_{P}$.

Given $M_{P B}=M_{P I}$ in ShoMig Equilibrium, we can pair off emigrants with immigrants. Combining previous inequalities, for each such pair $w_{C}-w_{P}-z_{P I}-m_{P I}>$ $\Delta r_{P}>m_{P B}$. An immigrant's real gain dominates the matching emigrant's real loss. Joining this with the fact that every Poor Border native turning cross-border seller clearly experiences positive real gain permits us to derive that aggregate willingness to pay in Poor is positive. Similar reasoning applies to Rich. We conclude that

$$
A W T P(\bar{\theta}, \underline{\theta}, 0,0)>0
$$

(c) Here we show that $A W T P\left(\bar{\theta}, \underline{\theta}, t_{P B}, t_{R B}\right)<0$ if $t_{P B}$ and $t_{R B}$ satisfy $N_{R}(\bar{\theta}-\underline{\theta})=$ $N_{P} t_{P B}+N_{R} t_{R B}$. - Surely, if each Rich Border resident became cross-border shopper and if no cross-border shopper or cross-border seller incurred any cultural or mobility $\operatorname{cost} A W T P(\bar{\theta}, \underline{\theta}, 0,0)$ could attain its maximum of $N_{R}(\bar{\theta}-\underline{\theta})$. Yet sellers do exhibit cultural and mobility costs. Hence $\operatorname{AWTP}(\bar{\theta}, \underline{\theta}, 0,0)$ generally must fall short of $N_{R}(\bar{\theta}-\underline{\theta})$. But then

$$
\begin{aligned}
A W T P\left(\bar{\theta}, \underline{\theta}, t_{P B}, t_{R B}\right) & =A W T P(\bar{\theta}, \underline{\theta}, 0,0)-N_{P} t_{P B}-N_{R} t_{R B} \\
& <N_{R}(\bar{\theta}-\underline{\theta})-N_{P} t_{P B}-N_{R} t_{R B}=0
\end{aligned}
$$

The first equality is repeated from the first line of (22). The last equality holds by assumption.

(d) Finally we show that $A W T P\left(\bar{\theta}, \underline{\theta}, t_{P B}, t_{R B}\right)>0$ for some (and hence even if) $t_{P B}, t_{R B}>0$. - First, note that $A W T P(\bar{\theta}, \underline{\theta}, 0,0)>0$ (see (b)). And second, note that $A W T P\left(\bar{\theta}, \underline{\theta}, t_{P B}^{\prime \prime}, t_{R B}^{\prime \prime}\right)<0$ for sufficiently large tax rates $t_{P B}^{\prime \prime}, t_{R B}^{\prime \prime}$ (see (c)). Third, note that $A W T P\left(\bar{\theta}, \underline{\theta}, t_{P B}, t_{R B}\right)$ is continuous in $t_{P B}$ and $t_{R B}$. Pick $c \in(0, A W T P(\bar{\theta}, \underline{\theta}, 0,0))$. By the intermediate value theorem there must exist $t_{P B}^{\prime}, t_{R B}^{\prime}>0$ such that $A W T P\left(\bar{\theta}, \underline{\theta}, t_{P B}^{\prime}, t_{R B}^{\prime}\right)=c>0$.

Part (ii): (a) Consider transaction costs $\underline{\theta}^{\prime} \in(0, \underline{\theta})$ and the corresponding individual utility level $U\left(m_{j k}, z_{j k}, \underline{\theta}^{\prime}, t_{j k}\right)$. By definition, the individual willingness-to-pay for a reduction in transaction costs from $\bar{\theta}$ to $\underline{\theta}^{\prime}$ can be written as

$$
\begin{aligned}
\Delta U\left(m_{j k}, z_{j k}, \bar{\theta}, \underline{\theta}^{\prime}, t_{j k}\right)= & U\left(m_{j k}, z_{j k}, \underline{\theta}^{\prime}, t_{j k}\right)-U\left(m_{j k}, z_{j k}, \underline{\theta}, 0\right) \\
& +U\left(m_{j k}, z_{j k}, \underline{\theta}, 0\right)-U\left(m_{j k}, z_{j k}, \bar{\theta}, 0\right) \\
= & \Delta U\left(m_{j k}, z_{j k}, \underline{\theta}, \underline{\theta}^{\prime}, t_{j k}\right)+\Delta U\left(m_{j k}, z_{j k}, \bar{\theta}, \underline{\theta}, 0\right) .
\end{aligned}
$$

Aggregating individuals' willingness-to-pay for this reduction then yields

$$
\begin{aligned}
A W T P\left(\bar{\theta}, \underline{\theta}^{\prime}, t_{P B}, t_{R B}\right) & =A W T P\left(\underline{\theta}, \underline{\theta}^{\prime}, t_{P B}, t_{R B}\right)+A W T P(\bar{\theta}, \underline{\theta}, 0,0) \\
& =A W T P\left(\underline{\theta}, \underline{\theta}^{\prime}, 0,0\right)+A W T P\left(\bar{\theta}, \underline{\theta}, t_{P B}, t_{R B}\right),
\end{aligned}
$$


where the last line follows from (24). Since $A W T P\left(\underline{\theta}, \underline{\theta}^{\prime}, 0,0\right)>0$, i.e., $A W T P$ for cutting transaction costs from $\underline{\theta}$ to $\underline{\theta}^{\prime}$ is strictly positive (see (23) with $\bar{\theta}=\underline{\theta}$ and $\left.\underline{\theta}=\underline{\theta}^{\prime}\right), A W T P\left(\bar{\theta}, \underline{\theta}^{\prime}, t_{P B}, t_{R B}\right)>A W T P\left(\bar{\theta}, \underline{\theta}, t_{P B}, t_{R B}\right)$ results, which proves the first part of Proposition 4 (ii).

(b) Finally, we prove that a decline in the initial transaction costs from $\bar{\theta}$ to $\bar{\theta}^{\prime}$ reduces $A W T P$. Consider transaction costs $\bar{\theta}^{\prime} \in(\underline{\theta}, \bar{\theta})$ and the corresponding individual utility level $U\left(m_{j k}, z_{j k}, \bar{\theta}^{\prime}, t_{j k}\right)$. Repeating the previous line of reasoning leads to

$$
\Delta U\left(m_{j k}, z_{j k}, \bar{\theta}, \underline{\theta}, t_{j k}\right)=\Delta U\left(m_{j k}, z_{j k}, \bar{\theta}^{\prime}, \underline{\theta}, t_{j k}\right)+\Delta U\left(m_{j k}, z_{j k}, \bar{\theta}, \bar{\theta}^{\prime}, 0\right) .
$$

Then, aggregating individuals' willingness-to-pay for this reduction results in

$$
A W T P\left(\bar{\theta}, \underline{\theta}, t_{P B}, t_{R B}\right)=A W T P\left(\bar{\theta}^{\prime}, \underline{\theta}, t_{P B}, t_{R B}\right)+A W T P\left(\bar{\theta}, \bar{\theta}^{\prime}, 0,0\right) .
$$

Since $A W T P\left(\bar{\theta}, \bar{\theta}^{\prime}, 0,0\right)>0$, i.e., $A W T P$ for cutting transaction costs from $\bar{\theta}$ to $\bar{\theta}^{\prime}$ is strictly positive (see again $(23)), A W T P\left(\bar{\theta}, \underline{\theta}, t_{P B}, t_{R B}\right)>A W T P\left(\bar{\theta}^{\prime}, \underline{\theta}, t_{P B}, t_{R B}\right)$ holds, which proves our statement.

Part (iii): Let us show that $A W T P$ is decreasing in $\bar{m}_{j}$. Our proof consists of two main arguments: First, the number of sales $Y$ declines, thereby reducing gross benefits from cross-border interaction. Second, cross-border sellers/shoppers and migrants with higher cultural and migration costs replace individuals with lower costs, thereby diminishing net benefits from the remaining sales. Both effects reduce $A W T P$. We consider a decline in $\bar{m}_{P}$, but the same line of reasoning can be applied with respect to a decline in $\bar{m}_{R}$.

(a) We start with identifying the decisive variables for $A W T P$ : A rise in $\bar{m}_{P}$ leads to a higher price $p_{C}$ (Proposition 3, Part (i)). This price increase in itself, i.e., for given sales $Y$, does not affect $A W T P$, since the additional gains of cross-border sellers are exactly matched by the decline in gains of cross-border shoppers. In this sense, changes in the price $p_{C}$ are neutral; it is sales $Y$ and the induced cultural and migration costs, $z_{j k}$ and $m_{j k}$, that are crucial.

(b) Next, we sum up the impact of $\bar{m}_{P}$ on the thresholds $\widetilde{z}_{P B}$ and $\widetilde{m}_{P B}$ and thus on the $z_{P k}-m_{P k}$ types who cross-border sell or migrate (see (7)-(9) and (11)): A rise in $\bar{m}_{P}$ from $\bar{m}_{P}^{\prime}$ to $\bar{m}_{P}^{\prime \prime}$ increases $\widetilde{m}_{P B}$ from $\widetilde{m}_{P B}^{\prime}$ to $\widetilde{m}_{P B}^{\prime \prime}$ (Proposition 3, Part (i) and (8)), $\widetilde{z}_{P B}$ from $\widetilde{z}_{P B}^{\prime}$ to $\widetilde{z}_{P B}^{\prime \prime}$ (Proposition 3, Part (i) and (7)), and $\widetilde{z}_{P B}-\widetilde{m}_{P B}$ from $\widetilde{z}_{P B}^{\prime}-\widetilde{m}_{P B}^{\prime}$ to $\widetilde{z}_{P B}^{\prime \prime}-\widetilde{m}_{P B}^{\prime \prime}$ (Lemma 1 and Proposition 3, Part (i)). The changes in Poor Border are illustrated in Figure 4.

(c) In addition, recall that $Y$ is decreasing in $\bar{m}_{P}$ (Proposition 3, Part (i)), $C_{P B}$ is increasing in $\bar{m}_{P}$ (Proposition 3, Part (ii)), and $M_{P I}=Y / b-C_{P B}$ must be decreasing in $\bar{m}_{P}$ (Proposition 3, Part (ii)).

(d) Next, we argue that, within the group of cross-border sellers, the 'number' of each high-cost type (i.e., $z_{P B}>\widetilde{z}_{P B}^{\prime}-\widetilde{m}_{P B}^{\prime}$ or $z_{P I}+m_{P I}>\widetilde{z}_{P B}^{\prime}-\widetilde{m}_{P B}^{\prime}$ ) increases 
in $\bar{m}_{P}$, whereas the 'number' of each low-cost type (i.e., $z_{P B} \leq \widetilde{z}_{P B}^{\prime}-\widetilde{m}_{P B}^{\prime}$ or $\left.z_{P I}+m_{P I} \leq \widetilde{z}_{P B}^{\prime}-\widetilde{m}_{P B}^{\prime}\right)$ decreases or remains constant. Since sales $Y$ decline, 'old' $z_{P k}-m_{P k}$ types who cross-border sell are replaced by 'new' $z_{P k}-m_{P k}$ types whose cultural and migration costs exceed those of the 'old' types. To this end, we subdivide Poor's cross-border sellers into six groups (see Figure 4 for illustration):

Group 1: Border natives with $z_{P B} \leq \widetilde{z}_{P B}^{\prime}-\widetilde{m}_{P B}^{\prime}$. The types of this group remain cross-border sellers. Moreover, a rise in $\bar{m}_{P}$ does not affect their number (i.e., $\left.N\left(\widetilde{z}_{P B}^{\prime}-\widetilde{m}_{P B}^{\prime}\right) \bar{m}_{P}^{\prime} /\left(\bar{z}_{P} \bar{m}_{P}^{\prime}\right)=N\left(\widetilde{z}_{P B}^{\prime}-\widetilde{m}_{P B}^{\prime}\right) \bar{m}_{P}^{\prime \prime} /\left(\bar{z}_{P} \bar{m}_{P}^{\prime \prime}\right)\right)$, nor does it affect the distribution of $z_{P B}$ within this group. The number of each $z_{P B}$-type remains unchanged.

Group 2: Border natives with $z_{P B} \in\left(\widetilde{z}_{P B}^{\prime}-\widetilde{m}_{P B}^{\prime}, \widetilde{z}_{P B}^{\prime}\right]$ and $z_{P B}-m_{P B} \leq \widetilde{z}_{P B}^{\prime}-\widetilde{m}_{P B}^{\prime}$. The types of group 2 also remain cross-border sellers. Simple calculation shows that a rise in $\bar{m}_{P}$ from $\bar{m}_{P}^{\prime}$ to $\bar{m}_{P}^{\prime \prime}$ increases the group's size, i.e., 'new' size > 'old' size $\Leftrightarrow$

$$
\begin{aligned}
& \frac{\left[\widetilde{z}_{P B}^{\prime}-\left(\widetilde{z}_{P B}^{\prime}-\widetilde{m}_{P B}^{\prime}\right)\right] \bar{m}_{P}^{\prime \prime}-0.5\left(\widetilde{m}_{P B}^{\prime}\right)^{2}}{\bar{z}_{P} \bar{m}_{P}^{\prime \prime}} N \\
> & \frac{\left[\widetilde{z}_{P B}^{\prime}-\left(\widetilde{z}_{P B}^{\prime}-\widetilde{m}_{P B}^{\prime}\right)\right] \bar{m}_{P}^{\prime}-0.5\left(\widetilde{m}_{P B}^{\prime}\right)^{2}}{\bar{z}_{P} \bar{m}_{P}^{\prime}} N
\end{aligned}
$$

and similarly the 'number' of each $z_{P B}$-type within this group. Consequently, the types of this group provide additional cross-border sellers with cultural costs $z_{P B}>\widetilde{z}_{P B}^{\prime}-\widetilde{m}_{P B}^{\prime}$. Since the size of group 1 remains unchanged and the amount of sales declines in response to a higher $\bar{m}_{P}$, these additional cross-border sellers replace Poor Interior natives whose cultural and mobility costs would have amounted to $z_{P I}+m_{P I} \leq \widetilde{z}_{P B}^{\prime}-\widetilde{m}_{P B}^{\prime}$ (see (11)). Comparing costs reveals that the costs of the 'new' sellers exceed those of the 'old' ones, i.e., $z_{P B}>\widetilde{z}_{P B}^{\prime}-\widetilde{m}_{P B}^{\prime} \geq z_{P I}+m_{P I}$.

Group 3: Border natives with $z_{P B} \in\left(\widetilde{z}_{P B}^{\prime}, \widetilde{z}_{P B}^{\prime \prime}\right], z_{P B}-m_{P B} \leq \widetilde{z}_{P B}^{\prime \prime}-\widetilde{m}_{P B}^{\prime \prime}$, and $m_{P B}>\tilde{m}_{P B}^{\prime}$. These types now switch from $(P B, P B)$ to $(P B, R B)$ and again replace Poor Interior natives as cross-border sellers. The resulting cultural costs again exceed those of the Poor Interior natives who are replaced, i.e., $z_{P B}>\widetilde{z}_{P B}^{\prime}>$ $\widetilde{z}_{P B}^{\prime}-\widetilde{m}_{P B}^{\prime} \geq z_{P I}+m_{P I}($ see $(11))$.

Group 4: Border natives with $z_{P B}-m_{P B} \in\left(\widetilde{z}_{P B}^{\prime}-\widetilde{m}_{P B}^{\prime}, \widetilde{z}_{P B}^{\prime \prime}-\widetilde{m}_{P B}^{\prime \prime}\right]$ and $m_{P B} \leq$ $\widetilde{m}_{P B}^{\prime}$. These types now switch from $(P B, P I)$ to $(P B, R B)$, leading to additional cultural costs $z_{P B}>\widetilde{z}_{P B}^{\prime}-\widetilde{m}_{P B}^{\prime}+m_{P B}$, but also releasing $m_{P B}$ by no longer emigrating to Poor Interior. Note that these types' net additional costs $z_{P B}-m_{P B}$ exceed the cultural and migration costs of those Poor Interior households replaced as cross-border sellers because $z_{P B}-m_{P B}>\widetilde{z}_{P B}^{\prime}-\widetilde{m}_{P B}^{\prime} \geq z_{P I}+m_{P I}$ (see again (11)).

Group 5: Interior natives with $z_{P I}+m_{P I} \in\left(\widetilde{z}_{P B}^{\prime}-\widetilde{m}_{P B}^{\prime}, \widetilde{z}_{P B}^{\prime \prime}-\widetilde{m}_{P B}^{\prime \prime}\right]$. These types now switch from $(P I, P I)$ to $(P I, P B)$, leading to cultural and migration 
costs $z_{P I}+m_{P I}>\widetilde{z}_{P B}^{\prime}-\widetilde{m}_{P B}^{\prime}$. Again, since $M_{P I}$ goes down in response to a higher $\bar{m}_{P}$, they replace 'old' type cross-border sellers native to Interior whose cultural and migration costs $z_{P I}+m_{P I} \leq \widetilde{z}_{P B}^{\prime}-\widetilde{m}_{P B}^{\prime}$ were below those of the 'new' types.

Group 6: Interior natives with $z_{P I}+m_{P I} \leq \widetilde{z}_{P B}^{\prime}-\widetilde{m}_{P B}^{\prime}$. The types of this group remain cross-border sellers. A rise in $\bar{m}_{P}$ reduces the number of each $z_{P I}-m_{P I}$ type within this group.

To sum up, 'old' $z_{P k}-m_{P k}$ types who cross-border sell are replaced by 'new' $z_{P k^{-}}$ $m_{P k}$ types whose cultural and migration costs exceed those of the 'old' types.

(e) In addition, 'old' $m_{P B}$ types who migrate from Border to Interior are replaced by 'new' $m_{P k}$ types whose migration costs exceed those of the 'old' types. Border natives with $z_{P B}-m_{P B}>\widetilde{z}_{P B}^{\prime \prime}-\widetilde{m}_{P B}^{\prime \prime}$ and $m_{P B} \in\left(\widetilde{m}_{P B}^{\prime}, \widetilde{m}_{P B}^{\prime \prime}\right]$ now switch from $(P B, P B)$ to $(P B, P I)$, causing migration costs $m_{P B}>\widetilde{m}_{P B}^{\prime}$. Since $M_{P I}$ and thus the number of migrants fall in response to a higher $\bar{m}_{P}$ (Proposition 3 (ii)), they replace 'old' type migrants native to Poor Border whose migration costs $m_{P B} \leq \widetilde{m}_{P B}^{\prime}$ would be below the ones of the 'new' migrants.

(f) To sum up, $A W T P$ decreases in $\bar{m}_{P}$ because of two reasons: first, a rise in $\bar{m}_{P}$ decreases the amount of sales $Y$. This reduces $A W T P$ since each sale positively contributes to real gains of cross-border shopping and thus to AWTP (which follows from Proposition 4, Proof of Part (i), (b)). The negative impact of a decline in sales on $A W T P$ will exist even if the cultural and migration costs of the remaining crossborder sellers/shoppers and migrants remain unchanged. This affects both countries, Rich and Poor, negatively. Second, cross-border sellers and migrants with higher cultural and migration costs replace individuals with lower costs in Poor. This further diminishes $A W T P$. (Such a replacement effect only concerns Poor and does not occur in Rich.) We conclude that $A W T P$ decreases in $\bar{m}_{P}$.

\section{Proof of Proposition 5: Voting and Aggregate Willingness to Pay}

On the one hand, natives with $z_{j B} \leq \widetilde{z}_{j B}^{V}$ benefit from, and approve of, integration. Following Table 1's entry for $(P B, R B))$ and employing (17), a given beneficiary's utility gain is $\left(\widetilde{z}_{j B}^{V}-z_{j B}\right)$. The beneficiaries' average gain is $\left(\widetilde{z}_{j B}^{V}\right) / 2$. Since the beneficiaries' total number is $\left(\widetilde{z}_{j B}^{V}\right)\left(N_{j} / \bar{z}_{j}\right)$, their aggregate gain is simply $\left(\widetilde{z}_{j B}^{V}\right)^{2}\left(N_{j} / 2 \bar{z}_{j}\right)$. On the other hand, natives with $z_{j B}>\widetilde{z}_{j B}^{V}$ suffer from, and hence vote against, the project. Because losers not necessarily cross-border-trade (since they often do better by withdrawing from cross-border trade altogether) individual loss at most equals (and, in fact, often strictly falls short of) $\left(z_{j B}-\widetilde{z}_{j B}^{V}\right)$. The losers' average loss must be strictly smaller than $\left(\bar{z}_{j}-\widetilde{z}_{j B}^{V}\right) / 2$. Because the losers' total is $\left(\bar{z}_{j}-\widetilde{z}_{j B}^{V}\right)\left(N_{j} / \bar{z}_{j}\right)$, Border's aggregate loss must strictly fall short of $\left(\bar{z}_{j}-\widetilde{z}_{j B}^{V}\right)^{2}\left(N_{j} / 2 \bar{z}_{j}\right)$.

With absentee ownership and a uniform distribution of households, approval requires $\widetilde{z}_{j B}^{V}>\bar{z}_{j}-\widetilde{z}_{j B}^{V}$. The comparision of aggregate gains with aggregate losses reveals the former to dominate the latter, within either border region. 
Finally, Interior natives always are better off, given their ownership of Border land combined with the fact that Border rents rise along with integration.

\section{Proof of Proposition 6: Voting and Mobility}

Part (i): In the scenario of absentee ownership, $\widetilde{z}_{P B}^{V}=\widetilde{z}_{P B}-\widetilde{m}_{P B}$ (see (17)). Since $\widetilde{z}_{P B}-\widetilde{m}_{P B}$ is increasing in $p_{C}$ (Lemma 1 ), and since $p_{C}$ is increasing in $\bar{m}_{P}$ (Proposition 3, Part (i), (a)), $\widetilde{z}_{P B}^{V}$ is increasing in $\bar{m}_{P}$.

Since $V_{P B}$ is increasing in $\widetilde{z}_{P B}^{V}$ (see (18)), and since $\widetilde{z}_{P B}^{V}$ is increasing in $\bar{m}_{P}, V_{P B}$ is increasing in $\bar{m}_{P}$. Similar reasoning applies to the response of $V_{R B}$ to a change in $\bar{m}_{R}$.

Part (ii): (a) Consider the extreme case with $t_{P B}=t_{R B}=0$ first. Note that then $\widetilde{z}_{P B}^{V}=$ $\widetilde{z}_{P B}$ (see (17)) and $\widetilde{m}_{P B}^{V}=\widetilde{m}_{P B}$ (see (16)). But then $V_{P B}=C_{P B}+M_{P B}=Y / b$. Since $Y / b$ is decreasing in $\bar{m}_{P}$ (Proposition 3, Part (i), (c)), $V_{P B}$ is decreasing in $\bar{m}_{P}$.

(b) We now turn to the general case where taxes are non-negative. Suppose $\bar{m}_{P}^{\prime}<$ $\bar{m}_{P}^{\prime \prime}$. Define the increment in Poor Border votes due to the increase in Poor's mobility cost parameter as $\Delta V_{P B}\left(\bar{m}_{P}^{\prime}, \bar{m}_{P}^{\prime \prime}, t_{P B}\right)=V_{P B}\left(\bar{m}_{P}^{\prime \prime}, t_{P B}\right)-V_{P B}\left(\bar{m}_{P}^{\prime}, t_{P B}\right)$. Also, define the critical values following from $\bar{m}_{P}^{\prime}$ and $t_{P B}\left(\bar{m}_{P}^{\prime \prime}\right.$ and $\left.t_{P B}\right)$ as $\widetilde{m}_{P B}^{\prime}, \widetilde{z}_{P B}^{\prime}$, etc. $\left(\widetilde{m}_{P B}^{\prime \prime}, \widetilde{z}_{P B}^{\prime \prime}\right.$, etc.). Note first that $\Delta V_{P B}\left(\bar{m}_{P}^{\prime}, \bar{m}_{P}^{\prime \prime}, 0\right)<0$ (see (a)). Moreover, for $\bar{m}_{P}=\bar{m}_{P}^{\prime}, \operatorname{tax} t_{P B}=\left(\widetilde{z}_{P B}^{\prime}\right)^{2} /\left(2 \bar{z}_{P}\right)$ implies $\Delta r_{P}=0$ (see (12)). Then, $\widetilde{m}_{P B}^{\prime}=t_{P B}$ (see (8) and thus $\left(\widetilde{m}_{P B}^{V}\right)^{\prime}=\widetilde{m}_{P B}^{\prime}-t_{P B}=0$ (see (16) with $\alpha=1$ ), leading to $V_{P B}\left(\bar{m}_{P}^{\prime},\left(\widetilde{z}_{P B}^{\prime}\right)^{2} / 2 \bar{z}_{P}\right)=\left(\widetilde{z}_{P B}^{V}\right)^{\prime} / \bar{z}_{P}$ (see (18)). Using this result and the supporters' share (18) yield

$$
\begin{aligned}
\Delta V_{P B}\left(\bar{m}_{P}^{\prime}, \bar{m}_{P}^{\prime \prime}, \frac{\left(\widetilde{z}_{P B}^{\prime}\right)^{2}}{2 \bar{z}_{P}}\right) & =V_{P B}\left(\bar{m}_{P}^{\prime \prime}, \frac{\left(\widetilde{z}_{P B}^{\prime}\right)^{2}}{2 \bar{z}_{P}}\right)-V_{P B}\left(\bar{m}_{P}^{\prime}, \frac{\left(\widetilde{z}_{P B}^{\prime}\right)^{2}}{2 \bar{z}_{P}}\right) \\
& =\frac{\left(\widetilde{z}_{P B}^{V}\right)^{\prime \prime}-\left(\widetilde{z}_{P B}^{V}\right)^{\prime}}{\bar{z}_{P}}+\frac{\left(\widetilde{m}_{P B}^{V}\right)^{\prime \prime}\left[\bar{z}_{P}-\left(\widetilde{z}_{P B}^{V}\right)^{\prime \prime}\right]}{\bar{m}_{P} \bar{z}_{P}}>0 .
\end{aligned}
$$

The first term on the RHS is positive because $\left(\widetilde{z}_{P B}^{V}\right)^{\prime \prime}>\left(\widetilde{z}_{P B}^{V}\right)^{\prime}$ - recall that $\widetilde{z}_{P B}^{V}$ increase in $\widetilde{z}_{P B}$, (see (17) with $\alpha=1$ ), which in turn increases in $\bar{m}_{P}$. The second term is obviously non-negative.

Finally, note that $\Delta V_{P B}\left(\bar{m}_{P}^{\prime}, \bar{m}_{P}^{\prime \prime}, t_{P B}\right)$ is a continuous function of tax $t_{P B}$ on the interval $\left[0,\left(\widetilde{z}_{P B}\right)^{2} /\left(2 \bar{z}_{P}\right)\right]$. By the intermediate value theorem, there must exist two critical tax values $t_{P B}^{c v 1} \in\left(0,\left(\widetilde{z}_{P B}\right)^{2} /\left(2 \bar{z}_{P}\right)\right)$ and $t_{P B}^{c v 2} \in\left(0,\left(\widetilde{z}_{P B}\right)^{2} /\left(2 \bar{z}_{P}\right)\right), t_{P B}^{c v 1}<t_{P B}^{c v 2}$, such that (i) $\Delta V_{P B}\left(\bar{m}_{P}^{\prime}, \bar{m}_{P}^{\prime \prime}, t_{P B}\right)<0$ if $t_{P B} \in\left[0, t_{P B}^{c v 1}\right)$ and (ii) $\Delta V_{P B}\left(\bar{m}_{P}^{\prime}, \bar{m}_{P}^{\prime \prime}, t_{P B}\right)>$ 0 if $t_{P B} \in\left(t_{P B}^{c v 2},\left(\widetilde{z}_{P B}\right)^{2} /\left(2 \bar{z}_{P}\right)\right]$. Since $t_{P B}=\left(\widetilde{z}_{P B}\right)^{2} / 2 \bar{z}_{P}$ is the largest tax level compatible with an 'interior' solution, i.e., with $\widetilde{m}_{P B}^{V} \geq 0$, it constitutes the upper tax boundary of our analysis. The results will, however, still hold if we consider boundary solutions. - A similar line of reasoning applies to the response of $V_{R B}$ to a change in $\bar{m}_{R}$. 
Part (iii): Note first that $p_{C}$ is decreasing in $\bar{m}_{R}$ (Proposition 3, Part (i)). Since $\Delta r_{P}$ is increasing in $p_{C}$ given (12), since $\widetilde{m}_{P B}$ is increasing in $\Delta r_{P}$ given (8) and since $\widetilde{m}_{P B}^{V}$ is increasing in $\widetilde{m}_{P B}$ given (16), $\widetilde{m}_{P B}^{V}$ is decreasing in $\bar{m}_{R}$.

Moreover, since $\widetilde{z}_{P B}^{V}$ is increasing in $p_{C}$ (see (17), (7) and Lemma 1), and since $p_{C}$ is decreasing in $\bar{m}_{R}$ (Proposition 3, Part (i)), $\widetilde{z}_{P B}^{V}$ is decreasing in $\bar{m}_{R}$.

We conclude that $V_{P B}$ is decreasing in $\bar{m}_{R}$, too. A similar argument applies to the response of $V_{R B}$ to a change in $\bar{m}_{P}$.

\section{Proof of Proposition 7: Voting and Inter(National) Policies}

Part (i): In the scenario of absentee ownership, $\widetilde{z}_{P B}^{V}=\widetilde{z}_{P B}-\widetilde{m}_{P B}$ (see (17)). Since $\widetilde{z}_{P B}-\widetilde{m}_{P B}$ is increasing in $p_{C}$ (Lemma 1 ), and since $p_{C}$ is decreasing in $\underline{\theta}$ (Proposition 2, Part (i)), then $\widetilde{z}_{P B}^{V}$ is decreasing in $\underline{\theta}$. Thus, $V_{P B}$ is decreasing in $\underline{\theta}$ in the case where $\alpha_{P}=0$.

In the case of native ownership, $\widetilde{z}_{P B}^{V}=\widetilde{z}_{P B}-t_{P B}$ (see (17)). Since $\widetilde{z}_{P B}$ is increasing in $p_{C}$, and since $p_{C}$ is decreasing in $\underline{\theta}$ (Proposition 2, Part (i)), $\widetilde{z}_{P B}^{V}$ is decreasing in $\underline{\theta}$. - Moreover, $\Delta r_{P}$ is decreasing in $\underline{\theta}$ (Proposition 2, Part (i)). But then $\widetilde{m}_{P B}^{V}=\Delta r_{P}$ also is decreasing in $\underline{\theta}$ (see (8)). Thus, $V_{P B}$ is decreasing in $\underline{\theta}$ in the case where $\alpha_{P}=1$, too.

Similar reasoning applies to the response of $V_{R B}$ to a change in $\bar{m}_{R}$.

Part (ii): Relaxing Assumption 1, we assume now that, without project implementation, transaction costs are $\bar{\theta}^{\prime}<p_{R}-p_{P}$. Let variables' equilibrium values obtained for $\theta=\bar{\theta}^{\prime}$ be indexed by one prime, and variables' equilibrium values obtained for $\theta=\underline{\theta}$ by two primes. E.g., $w_{C}^{\prime}$ is the equilibrium wage of cross-border sellers for initial transaction cost $\bar{\theta}^{\prime}$, while $w_{C}^{\prime \prime}$ is the respective wage for post-project transaction cost $\underline{\theta}$. (Consequently, $\widetilde{z}_{P B}^{\prime}=w_{C}^{\prime}-w_{P}, \widetilde{z}_{P B}^{\prime \prime}=w_{C}^{\prime \prime}-w_{P}$ etc.) We first analyse who supports a project that reduces transaction costs from $\bar{\theta}^{\prime}$ to $\underline{\theta}$. Then we compare the supporters' share in this case with the share that would result if transaction costs fell from $\bar{\theta}=p_{R}-p_{P}$ to $\underline{\theta}$. Again the focus is on Poor, but the same line of reasoning can be applied to analyse the situation in Rich.

(a) With absentee ownership $(\alpha=0)$, only individuals who cross-border sell for $\theta=\underline{\theta}$ might support the project that cuts transaction costs from $\bar{\theta}^{\prime}$ to $\underline{\theta}$. These individuals, who choose $(P B, R B)$ for $\theta=\underline{\theta}$, can be subdivided into three groups, depending on their optimal choice for $\theta=\bar{\theta}^{\prime}<p_{R}-p_{P}$. We analyse the support for the project within each of these three groups in turn.

Group 1: Households who choose $(P B, R B)$ for $\theta=\bar{\theta}^{\prime}$ and $(P B, R B)$ for $\theta=\underline{\theta}$ (types with $z_{P B} \leq \widetilde{z}_{P B}^{\prime}$ and $z_{P B} \leq \widetilde{z}_{P B}^{\prime}-\widetilde{m}_{P B}^{\prime}+m_{P B}=\widehat{z}_{P B}^{\prime}$ ). The integration 
project's benefit for a household of this group is

$$
\begin{aligned}
\left.\Delta U\right|_{\text {Group } 1} & =w_{C}^{\prime \prime}-w_{C}^{\prime}-\left(r_{P B}^{\prime \prime}+t_{P B}^{\prime \prime}-r_{P B}^{\prime}\right) \\
& =w_{C}^{\prime \prime}-w_{P}-\left(w_{C}^{\prime}-w_{P}\right)-\left[r_{P B}^{\prime \prime}-d_{P}+t_{P B}^{\prime \prime}-\left(r_{P B}^{\prime}-d_{P}\right)\right] \\
& =\widetilde{z}_{P B}^{\prime \prime}-\widetilde{m}_{P B}^{\prime \prime}-\left(\widetilde{z}_{P B}^{\prime}-\widetilde{m}_{P B}^{\prime}\right),
\end{aligned}
$$

where we used (7) and (8). The following reasoning uses the fact that $\widetilde{m}_{P B}=$ $\Delta r_{P}+t_{P B}=\widetilde{z}_{P B}^{2} / 2 \bar{z}_{P}$ only depends on $p_{C}$, which in turn is independent of $t_{P B}$ (Proposition 2, Part (iii)). Thus, neither $\widetilde{m}_{P B}$ nor $\widetilde{z}_{P B}-\widetilde{m}_{P B}$ is affected by $t_{P B}$. Since $\widetilde{z}_{P B}-\widetilde{m}_{P B}$ is increasing in $p_{C}$ (Lemma 1 ) and $p_{C}$ is decreasing in $\theta$ (Proposition 2, Part (i)), $\widetilde{z}_{P B}-\widetilde{m}_{P B}$ is decreasing in $\theta$. Thus, $\widetilde{z}_{P B}^{\prime \prime}-\widetilde{m}_{P B}^{\prime \prime}>\widetilde{z}_{P B}^{\prime}-\widetilde{m}_{P B}^{\prime}$ and $\left.\Delta U\right|_{\text {Group } 1}>0$. Consequently, all households that already cross-border sell at $\theta=\bar{\theta}^{\prime}$ and continue to cross border sell at $\theta=\underline{\theta}$ support the project.

Group 2: Households that choose $(P B, P I)$ for $\theta=\bar{\theta}^{\prime}$ and $(P B, R B)$ for $\theta=\underline{\theta}$ (types with $m_{P B} \leq \widetilde{m}_{P B}^{\prime}, z_{P B}>\widetilde{z}_{P B}^{\prime}-\widetilde{m}_{P B}^{\prime}+m_{P B}$ and $z_{P B} \leq \widetilde{z}_{P B}^{\prime \prime}-\widetilde{m}_{P B}^{\prime \prime}+m_{P B}$ ). Each of this group's household benefit from the project is

$$
\begin{aligned}
\left.\Delta U\right|_{\text {Group } 2} & =w_{C}^{\prime \prime}-w_{P}-z_{P B}-\left(r_{P B}^{\prime \prime}+t_{P B}-d_{P}-m_{P B}\right) \\
& =\widetilde{z}_{P B}^{\prime \prime}-\widetilde{m}_{P B}^{\prime \prime}-\left(z_{P B}-m_{P B}\right) \geq 0,
\end{aligned}
$$

where $\left.\Delta U\right|_{\text {Group } 2} \geq 0$ directly follows from the group's characteristic $z_{P B} \leq \widetilde{z}_{P B}^{\prime \prime}-$ $\widetilde{m}_{P B}^{\prime \prime}+m_{P B}$. Thus all households that migrate to Interior for $\theta=\bar{\theta}^{\prime}$ and cross-border sell for $\theta=\underline{\theta}$ support the project.

Group 3: Households that choose $(P B, P B)$ for $\theta=\bar{\theta}^{\prime}$ and $(P B, R B)$ for $\theta=\underline{\theta}$ (types with $z_{P B}>\widetilde{z}_{P B}^{\prime}, m_{P B}>\widetilde{m}_{P B}^{\prime}, z_{P B} \leq \widetilde{z}_{P B}^{\prime \prime}-\widetilde{m}_{P B}^{\prime \prime}+m_{P B}$ and $z_{P B} \leq \widetilde{z}_{P B}^{\prime \prime}$ ). Following the arguments above, a household in this group experiences a benefit of

$$
\begin{aligned}
\left.\Delta U\right|_{\text {Group } 3} & =w_{C}^{\prime \prime}-w_{P}-z_{P B}-\left(r_{P B}^{\prime \prime}+t_{P B}-r_{P B}^{\prime}\right) \\
& =\widetilde{z}_{P B}^{\prime \prime}-\widetilde{m}_{P B}^{\prime \prime}-\left(z_{P B}-\widetilde{m}_{P B}^{\prime}\right)
\end{aligned}
$$

This expression is positive, i.e., $\left.\Delta U\right|_{\text {Group } 3} \geq 0$, if $z_{P B} \leq \widetilde{z}_{P B}^{\prime \prime}-\widetilde{m}_{P B}^{\prime \prime}+\widetilde{m}_{P B}^{\prime}=:\left(\widetilde{z}_{P B}^{V}\right)^{\prime \prime}$ holds. Since $\left(\widetilde{z}_{P B}^{V}\right)^{\prime \prime} \in\left(\widetilde{z}_{P B}^{\prime}, \widetilde{z}_{P B}^{\prime \prime}\right)$, some but not all of the households of group 3 support the project.

(b) To sum up, in the case of $\bar{\theta}^{\prime}<p_{R}-p_{P}$, the project is supported by all households with $z_{P B} \leq \widetilde{z}_{P B}^{\prime \prime}-\widetilde{m}_{P B}^{\prime \prime}+m_{P B}$ and $z_{P B} \leq \widetilde{z}_{P B}^{\prime \prime}-\widetilde{m}_{P B}^{\prime \prime}+\widetilde{m}_{P B}^{\prime}$. The set of supporters contains all households of groups 1 and 2 and some households of group 3. By contrast, in the case of $\bar{\theta}=p_{R}-p_{P}$, support merely comes from those households that satisfy $z_{P B} \leq \widetilde{z}_{P B}^{\prime \prime}-\widetilde{m}_{P B}^{\prime \prime}=\widetilde{z}_{P B}^{V}$ (Equation (17)). Thus, support is unequivocally smaller in the case of $\bar{\theta}=p_{R}-p_{P}$ than in the case of $\bar{\theta}^{\prime}<p_{R}-p_{P}$. 


\section{Proof of Proposition 8: Voting and Federal Grants}

We turn to the case of absentee ownership $(\alpha=0)$ first. Note that $\widetilde{z}_{j B}-\widetilde{m}_{j B}$ does not vary with $t_{j B}$ (Proposition 2, Proof of Part (iii)). But then neither does $\widetilde{z}_{j B}^{V} / \bar{z}_{j}$. That is, then neither does $V_{j B}$ (see (18)). Supporters' numbers are constant with respect to $t_{j B}$, and hence with respect to grant $s_{j}$.

We turn to the case of native ownership $(\alpha=1)$ next. Note that $\widetilde{z}_{j B}$ is constant in $t_{j B}$ (Proposition 2, Proof of Part (iii)), while $-t_{j B}$ obviously is decreasing in $t_{j B}$. But then $\widetilde{z}_{j B}^{V}=\widetilde{z}_{j B}-t_{j B}$ is a decreasing function of $t_{j B}$. Moreover, for $\alpha=1$, $\widetilde{m}_{j B}^{V}=\widetilde{m}_{j B}-t_{j B}=\Delta r_{j B}$ is decreasing in $t_{j B}$ because $\Delta r_{j B}$ is decreasing in $t_{j B}$ (see (16) and Proposition 2, Part (iii)). Supporters' numbers are decreasing in $t_{j B}$, and hence increasing in grant $s_{j}$. 


\section{CESifo Working Paper Series}

for full list see www.cesifo-group.org/wp

(address: Poschingerstr. 5, 81679 Munich, Germany, office@cesifo.de)

2217 Hartmut Egger and Peter Egger, The Trade and Welfare Effects of Mergers in Space, February 2008

2218 Dorothee Crayen and Joerg Baten, Global Trends in Numeracy 1820-1949 and its Implications for Long-Run Growth, February 2008

2219 Stephane Dees, M. Hashem Pesaran, L. Vanessa Smith and Ron P. Smith, Identification of New Keynesian Phillips Curves from a Global Perspective, February 2008

2220 Jerome L. Stein, A Tale of Two Debt Crises: A Stochastic Optimal Control Analysis, February 2008

2221 Michael Melvin, Lukas Menkhoff and Maik Schmeling, Automating Exchange Rate Target Zones: Intervention via an Electronic Limit Order Book, February 2008

2222 Raymond Riezman and Ping Wang, Preference Bias and Outsourcing to Market: A Steady-State Analysis, February 2008

2223 Lars-Erik Borge and Jørn Rattsø, Young and Old Competing for Public Welfare Services, February 2008

2224 Jose Apesteguia, Steffen Huck, Jörg Oechssler and Simon Weidenholzer, Imitation and the Evolution of Walrasian Behavior: Theoretically Fragile but Behaviorally Robust, February 2008

2225 Walter Krämer, Long Memory with Markov-Switching GARCH, February 2008

2226 António Afonso and Christophe Rault, What do we really Know about Fiscal Sustainability in the EU? A Panel Data Diagnostic, February 2008

2227 Sergey M. Kadochnikov and Igor M. Drapkin, Market Structure, Technological Gap and Vertical Linkage Effects from Foreign Direct Investment, February 2008

2228 Guglielmo Maria Caporale, Davide Ciferri and Alessandro Girardi, Fiscal Shocks and Real Exchange Rate Dynamics: Some Evidence for Latin America, February 2008

2229 Scott Alan Carson, Geography and Insolation in $19^{\text {th }}$ Century US African-American and White Statures, February 2008

2230 Wolfgang Buchholz and Jan Schumacher, Discounting and Welfare Analysis Over Time: Choosing the $\eta$, February 2008

2231 M. Hashem Pesaran, Christoph Schleicher and Paolo Zaffaroni, Model Averaging in Risk Management with an Application to Futures Markets, February 2008 
2232 Wilhelm Kohler, Offshoring: Why Do Stories Differ?, February 2008

2233 Stefan Bach, Giacomo Corneo and Viktor Steiner, Effective Taxation of Top Incomes in Germany, 1992-2002, February 2008

2234 Robert S. Chirinko, $\sigma:$ The Long And Short Of It, February 2008

2235 Volker Grossmann and Holger Strulik, Should Continued Family Firms Face Lower Taxes than other Estates?, February 2008

2236 Guido Tabellini, The Scope of Cooperation: Values and Incentives, February 2008

2237 Heinrich W. Ursprung and Christian Wiermann, Reputation, Price, and Death: An Empirical Analysis of Art Price Formation, March 2008

2238 Hans Fehr and Christian Habermann, Private Retirement Savings in Germany: The Structure of Tax Incentives and Annuitization, March 2008

2239 Joseph Francois and Ian Wooton, Market Structure and Market Access, March 2008

2240 Hiroyuki Kasahara and Beverly Lapham, Productivity and the Decision to Import and Export: Theory and Evidence, March 2008

2241 Gary E. Bolton and Axel Ockenfels, Does Laboratory Trading Mirror Behavior in Real World Markets? Fair Bargaining and Competitive Bidding on EBay, March 2008

2242 Atsushi Oshima, B. Ravikumar and Raymond Riezman, Entrepreneurship, Organization Capital and the Evolution of the Firm, March 2008

2243 Walter Krämer and Sebastian Schich, Large-Scale Disasters and the Insurance Industry, March 2008

2244 Leif Danziger, Adjustment Costs, Inventories and Output, March 2008

2245 Anne van Aaken, Lars P. Feld and Stefan Voigt, Power over Prosecutors Corrupts Politicians: Cross Country Evidence Using a New Indicator, March 2008

2246 Hans-Christian Heinemeyer, Max-Stephan Schulze and Nikolaus Wolf, Endogenous Borders? The Effects of New Borders on Trade in Central Europe 1885-1933, March 2008

2247 Johannes Becker and Clemens Fuest, Tax Competition - Greenfield Investment versus Mergers and Acquisitions, March 2008

2248 Giorgio Bellettini and Hubert Kempf, Why not in your Backyard? On the Location and Size of a Public Facility, March 2008

2249 Jose Luis Evia, Roberto Laserna and Stergios Skaperdas, Socio-Political Conflict and Economic Performance in Bolivia, March 2008 
2250 Bas Jacobs and A. Lans Bovenberg, Optimal Taxation of Human Capital and the Earnings Function, March 2008

2251 Jan-Egbert Sturm and Timo Wollmershäuser, The Stress of Having a Single Monetary Policy in Europe, March 2008

2252 Guido Schwerdt, Labor Turnover before Plant Closure: 'Leaving the Sinking Ship' vs. 'Captain Throwing Ballast Overboard', March 2008

2253 Keith E. Maskus and Shuichiro Nishioka, Development-Related Biases in Factor Productivities and the HOV Model of Trade, March 2008

2254 Jeremy Edwards and Sheilagh Ogilvie, Contract Enforcement, Institutions and Social Capital: the Maghribi Traders Reappraised, March 2008

2255 Imed Drine and Christophe Rault, Purchasing Power Parity for Developing and Developed Countries. What can we Learn from Non-Stationary Panel Data Models?, March 2008

2256 Scott Alan Carson, Health, Wealth and Inequality: a Contribution to the Debate about the Relationship between Inequality and Health, March 2008

2257 C.A.E. Goodhart, The Regulatory Response to the Financial Crisis, March 2008

2258 Stefan Bauernschuster, Oliver Falck and Stephan Heblich, The Impact of Continuous Training on a Firm's Innovations, March 2008

2259 Michael Grimm and Stephan Klasen, Geography vs. Institutions at the Village Level, March 2008

2260 Fwu-Ranq Chang, Property Insurance, Portfolio Selection and their Interdependence, March 2008

2261 J. Atsu Amegashie and Marco Runkel, The Paradoxes of Revenge in Conflicts, March 2008

2262 Hans Jarle Kind, Marko Koethenbuerger and Guttorm Schjelderup, Efficiency Enhancing Taxation in Two-sided Markets, March 2008

2263 M. Hashem Pesaran, Til Schuermann and L. Vanessa Smith, Forecasting Economic and Financial Variables with Global VARs, March 2008

2264 Volker Grossmann, Entrepreneurial Innovation and Sustained Long-run Growth without Weak or Strong Scale Effects, March 2008

2265 Robert S. Chirinko and Huntley Schaller, The Irreversibility Premium, March 2008

2266 Andrea Galeotti and José Luis Moraga-González, Platform Intermediation in a Market for Differentiated Products, April 2008 
2267 Torben M. Andersen and Michael Svarer, The Role of Workfare in Striking a Balance between Incentives and Insurance in the Labour Market, April 2008

2268 Harald Badinger, Cyclical Fiscal Policy, Output Volatility, and Economic Growth, April 2008

2269 Thomas Aronsson and Erkki Koskela, Outsourcing and Optimal Nonlinear Taxation: A Note, April 2008

2270 Gary E. Bolton, Claudia Loebbecke and Axel Ockenfels, How Social Reputation Networks Interact with Competition in Anonymous Online Trading: An Experimental Study, April 2008

2271 Nikolaus Wolf, Scylla and Charybdis. Explaining Europe's Exit from Gold, January 1928 - December 1936, April 2008

2272 Michael Funke and Marc Gronwald, The Undisclosed Renminbi Basket: Are the Markets Telling us something about where the Renminbi - US Dollar Exchange Rate is Going?, April 2008

2273 Thor Olav Thoresen and Annette Alstadsæter, Shifts in Organizational Form under a Dual Income Tax System, April 2008

2274 Helge Berger and Volker Nitsch, Too many Cooks? Committees in Monetary Policy, April 2008

2275 Yin-Wong Cheung and Eiji Fujii, Deviations from the Law of One Price in Japan, April 2008

2276 Michael S. Michael, Sajal Lahiri and Panos Hatzipanayotou, Integrated Reforms of Indirect Taxes in the Presence of Pollution, April 2008

2277 Bas Jacobs, Is Prescott Right? Welfare State Policies and the Incentives to Work, Learn and Retire, April 2008

2278 Burkhard Heer and Alfred Maußner, Value Function Iteration as a Solution Method for the Ramsey Model, April 2008

2279 Jarko Fidrmuc and Christa Hainz, Integrating with their Feet: Cross-Border Lending at the German-Austrian Border, April 2008

2280 Kristof Dascher and Alexander Haupt, The Political Economy of Regional Integration Projects at Borders where Rich and Poor Meet: The Role of Cross-Border Shopping and Community Sorting, April 2008 